\title{
An improved artificial bee colony algorithm for flexible job-shop scheduling problem with fuzzy processing time
}

\author{
Kai Zhou Gao ${ }^{\mathrm{a}, \mathrm{b}}$, Ponnuthurai Nagaratnam Suganthan ${ }^{\mathrm{b}}$, Quan Ke Pan ${ }^{\mathrm{c}}$, Tay Jin Chua ${ }^{\mathrm{d}}$, Chin Soon Chong ${ }^{\mathrm{d}}$, Tian \\ Xiang Cai ${ }^{\mathrm{d}}$ \\ ${ }^{\text {a }}$ School of computer, Liaocheng University, Liaochheng, 252059, P. R. China \\ ${ }^{\mathrm{b}}$ School of Electrical and Electronic Engineering, Nanyang Technological University, 639798, Singapore \\ ${ }^{\mathrm{c}}$ State Key Lab of Digital Manufacturing Equipment \& Technology in Huazhong University of Science \& Technology, Wuhan, 430074, P. R. China \\ ${ }^{\mathrm{d}}$ Singapore Institute of Manufacturing Technology, Nanyang Drive 638075, Singapore \\ E-mail: gaokaizh@aliyun.com (Kaizhou Gao),EPNSUGAN@ntu.edu.sg (Suganthan), panquanke@qq.com (Pan), tjchua@simtech.a-star.edu.sg \\ (Chua), cschong@simtech.a-star.edu.sg (Chong), txcai@simtech.a-star.edu.sg (Cai).
}

\section{A R T I C L E I N F O}

Keywords:

Artificial bee colony algorithm

Flexible job-shop scheduling

Fuzzy processing time

Heuristic

\section{A B S T R A C T}

This study addresses flexible job-shop scheduling problem (FJSP) with fuzzy processing time. An improved artificial bee colony (IABC) algorithm is proposed for FJSP cases defined in existing literature and realistic instances in remanufacturing where the uncertainty of the processing time is modeled as fuzzy processing time. The objectives are to minimize the maximum fuzzy completion time and the maximum fuzzy machine workload, respectively. The goal is to make the scheduling algorithm as part of expert and intelligent scheduling system for remanufacturing decision support. A simple and effective heuristic rule is developed to initialize population. Extensive computational experiments are carried out using five benchmark cases and eight realistic instances in remanufacturing. The proposed heuristic rule is evaluated using five benchmark cases for minimizing the maximum fuzzy completion time and the maximum fuzzy machine workload objectives, respectively. IABC algorithm is compared to six meta-heuristics for maximum fuzzy completion time criterion. For maximum fuzzy machine workload, IABC algorithm is compared to six heuristics. The results and comparisons show that IABC algorithm can solve FJSP with fuzzy processing time effectively, both benchmark cases and real-life remanufacturing instances. For practical remanufacturing problem, the schedules by IABC algorithm can satisfy the requirement in real-life shop floor. The IABC algorithm can be as part of expert and intelligent scheduling system to supply decision support for remanufacturing scheduling and management.

\section{Introduction}

Flexible job shop scheduling problem (FJSP) is a generalization of the classical job shop scheduling problem (JSP). An operation can be processed on more than one machine in FJSP. To solve FJSP problem, two sub-problems have to be solved, machine assignment and operation sequencing. Machine assignment is to assign a processing machine for each operation. Operation sequencing is to schedule all operations on machines to obtain feasible and quality scheduling solution. FJSP is an NPhard problem (Bruker \& Schlie, 1990).

The first study to research FJSP was by Bruker and Schlie (Bruker \& Schlie, 1990) who proposed a polynomial algorithm for two jobs and identical machines FJSP problem. In recent years, many heuristics and meta-heuristics are employed for solving FJSP problem. These algorithms include tabu search (TS) (Brandimarte, 1993), genetic algorithm (GA) (Gao, Sun, \& Gen, 2008), particle swarm optimization (PSO) (Zhang, Shao, Li, \& Gao, 2009), parallel variable neighborhood search (PVNS)
(Yazdani, Amiri, \& Zandieh, 2010), artificial bee colony (ABC) ( Li, Pan \& Gao, 2011), discrete harmony search algorithm (DHS) (Gao, Suganthan \& Pan, 2014a; Gao, Suganthan \& Pan, 2014b), and hybrid algorithms based on different heuristics and metaheuristics. At the same time, many researchers focus on FJSP with different constraints or practical characteristics, for example fuzzy processing time (Lei, 2010; Lei, 2012; Wang \& Zhou, 2013; Wang \& Wang, 2013), energy consumption (Jiang \& Zuo, 2014), maintenance activity (Wang \& Yu, 2010), new job insertion (Gao, Suganthan \& Chua, 2015), limited resource (Karthikeyan, Asokan \& Nickolas, 2014), overlapping operations (Demir \& İşleyen, 2014), sequence-dependent setup and transportation time (Rossi, 2014), etc.

Among the meta-heuristics for FJSP, artificial bee colony (ABC) algorithm is a relatively recent meta-heuristic method developed by Karaboga (Karaboga, 2005). Originally, ABC algorithm was developed for solving the multi-variable and multi-modal continuous functions. Many researches show ABC algorithm's competitive performance for continuous and discrete 
optimization problems. In recent years, $\mathrm{ABC}$ algorithm is applied to solve shop scheduling problems successfully. Huang and Lin proposed an idle time based bee colony algorithm to solve open shop scheduling problems. Banharnsakun et al. (Banharnsakun, 2012) employed the best-so-far ABC (B-ABC) to solve job shop scheduling problem. Zhang (Zhang \& Wu, 2011) proposed an $\mathrm{ABC}$ algorithm for job shop scheduling problem with random processing times. Wang (Wang \& Zhou, 2012a; Wang \& Zhou, $2012 b$ ) designed two effective ABC algorithms for monoobjective and multi-objective FJSP. Thammano (Thammano \& Ajchara, 2013) designed a hybrid ABC algorithm with local search to solve FJSP. Li ( $\mathrm{Li}$, Pan \& Gao, 2011) proposed a Paretobased discrete ABC algorithm for multi-objective FJSP problem. Pan (Pan, Tasgetirern \& Suganthan, 2011) proposed a discrete ABC algorithm for the lot-streaming flow shop scheduling problem. A self-adaptive strategy was employed in the study to improve algorithm's performance.

Among practical characteristics, fuzzy processing time is considered in FJSP by many researchers. Lei proposed a decomposition-integration genetic algorithm (DIGA) (Lei, 2010) and a co-evolutionary genetic (CGA) (Lei, 2012) algorithm to minimize maximum fuzzy completion time. In these two papers, triangular fuzzy number (TFN) is used to represent the fuzzy processing time. Three TFN operators are employed to encode solution to a feasible scheduling solution. Wang and Zhou (Wang \& Zhou, 2013) proposed a hybrid artificial bee colony (HABC) algorithm for fuzzy flexible job shop scheduling problem. Several strategies are employed to initialize population. Left-shift decoding scheme, exploitation search procedures and variable neighborhood search (VNS) are used to improve performance. Wang et al (Wang \& Wang, 2013) developed an effective estimation of distribution algorithm (EDA) for fuzzy processing time FJSP problem. A probabilistic model is proposed to describe the probability distribution of the solution space. In both above literatures, Taguchi method is used to investigate the influence of parameters setting for algorithm performance. Compared to other algorithms, the EDA algorithm has the best competitive solutions for FJSP problem with fuzzy processing time.

In this study, we consider the remanufacturing scheduling problem with uncertainty in processing time of returns. Remanufacturing is the process of disassembly and recovery at the module level and, eventually, at the component level (Lund, 1984). Junior (Junior \& Filho, 2012) reviewed the literatures on production planning and control in remanufacturing. Seventy-six papers were examined and classified. However, there are few literatures on processing scheduling in remanufacturing. The uncertainty processing time of returns is one of seven major complicating characteristics in remanufacturing (Krupp, 1993; Ferguson, 2009). The uncertainty in processing time of returns cannot be controlled by remanufacturers. It is therefore important to handle this uncertainty in remanufacturing scheduling.

Existing ABC algorithms for FJSP do not solve remanufacturing scheduling with uncertainty in processing time.
Building on the successful application of ABC for solving FJSP, we propose an improved artificial bee colony (IABC) algorithm to solve remanufacturing scheduling problem with uncertainty in processing time of returns. As many discrete manufacturing systems, we model remanufacturing processes as FJSP problem and the uncertainty in processing time of returns is modeled as fuzzy processing time of FJSP. The objectives are to minimize the maximum fuzzy completion time and the maximum fuzzy machine workload, respectively. A simple and effective heuristic, named MinEnd, is proposed to initialize the population. To test performance, MinEnd is compared to several existing heuristics. IABC algorithm is tested using five benchmark cases and eight real instances from remanufacturing. The experimental results and comparisons show the competitiveness of IABC algorithm.

The rest of this paper is organized as follows: Section 2 briefly describes FJSP problem and fuzzy processing time constraint. Section 3 presents the basic $A B C$ algorithm and the IABC algorithm in detail. Section 4 discusses the experimental results and comparisons. We conclude this study in Section 5.

\section{FJSP with fuzzy processing time}

\subsection{Problem description}

In FJSP, each job consists of a sequence of operations. An operation can be executed by a set of candidate machines. Each operation of a job must be processed only on one machine at a time, while each machine can process only one operation at a time. The following notations and assumptions are used for the formulation of FJSP.

1. Let $J=\left\{J_{i}\right\}, 1 \leq i \leq n$, indexed $i$, be a set of $n$ jobs to be scheduled.

2. Let $M=\left\{M_{k}\right\}, 1 \leq k \leq m$, indexed $k$, be a set of $m$ machines.

3. Each job $J_{i}$ consists of a predetermined sequence of operations. Let $O_{i, h}$ be operation $h$ of $J_{i} \cdot q_{i}$ denotes the total number of operations of job $J_{i}$.

4. Each operation $O_{i, h}$ can be processed without interruption on one of a set of candidate machines $M\left(O_{i, h}\right)$. Let $P_{i, h, k}$ be the processing time of $O_{i, h}$ on machine $M_{k}$.

5. Decision variables

$$
x_{i, h, k}=\left\{\begin{array}{l}
1, \text { if machine } k \text { is selected for the operation } O_{i, h} \\
0, \text { otherwise }
\end{array}\right.
$$

$c_{i, h}$ denotes the completion time of the operation $O_{i, h}, c_{i}$

denotes the completion time of job $J_{i}$

6. The objectives are to minimize the Makespan and the maximum machine workload, respectively.

Makespan denoted by $C_{M}$, can be calculated by formula:

$$
\operatorname{Min} C_{M}=\max _{1 \leq i \leq n}\left\{c_{i}\right\}
$$


where $c_{i}$ is the completion time of job $i . c_{i}$ equals the value of $c_{i, h}$ when the value of $h$ is the $q_{i}$. Makespan is related to completion time of all jobs and the machine efficiency. If makespan value is reduced, it can shorten the job completion time and improve machine efficiency.

Maximum machine workload, denoted by $W_{M}$, can be calculated by formula:

$$
\operatorname{Min} W_{M}=\max _{1 \leq k \leq m}\left\{w_{k}\right\}
$$

where $w_{k}$ is the workload of machine $M_{k}$. $w_{k}$ equals the sum of $c_{i, h}$ where the value of $x_{i, h, k}$ is 1 . It means that the operation $O_{i, h}$ is processed on machine $k$.

The FJSP with fuzzy processing time means that the operation processing time is not an exact value and the processing time is shown as a triangular fuzzy number (TFN) as follows:

$$
t_{i, j, k}=\left(t_{i, j, k}^{1}, t_{i, j, k}^{2}, t_{i, j, k}^{3}\right)
$$

where $t_{i, j, k}^{1}$ and $t_{i, j, k}^{3}$ determine an interval of processing time while $t_{i, j, k}^{2}$ is the most probable processing time of operation $O_{i, j}$ on machine $M_{k}$.

The fuzzy completion time of operation $O_{i, j}$ is a TFN as follows:

$$
C_{i, j}=\left(C_{i, j}^{1}, C_{i, j}^{2}, C_{i, j}^{3}\right)
$$

where $C_{i, j}^{1}$ and $C_{i, j}^{2}$ are the minimum and maximum probable completion times of operation $O_{i, j} \cdot C_{i, j}^{3}$ is the most probable completion time of operation $O_{i, j}$.

The fuzzy machine workload of machine $M_{j}$ is also a TFN as follows:

$$
w_{j}=\left(w_{j}^{1}, w_{j}^{2}, w_{j}^{3}\right)
$$

where $w_{j}^{1}$ and $w_{j}^{2}$ are the minimum and maximum probable machine workload of $M_{j} \cdot w_{j}^{3}$ is the most probable machine workload of machine $M_{j}$.

\subsection{Operations on fuzzy processing time}

Addition operation, max operation and the ranking operation are three most important operations for TFNs. To compare and order TFN, these three operations are used in FJSP with fuzzy processing time. The addition operation is to compute fuzzy completion time. The max operation and the ranking operation are used to compare TFNs and obtain the maximum fuzzy completion time. The three operations are computed as follows: Addition operation: two TFNs, $t=\left(t_{1}, t_{2}, t_{3}\right)$ and $t^{\prime}=\left(t_{1}^{\prime}, t_{2}^{\prime}, t_{3}^{\prime}\right)$, their addition is as follows:

$$
t+t^{\prime}=\left(t_{1}+t_{1}^{\prime}, t_{2}+t_{2}^{\prime}, t_{3}+t_{3}^{\prime}\right)
$$

Ranking operation: three criteria are used to compare two TFNs $t=\left(t_{1}, t_{2}, t_{3}\right)$ and $t^{\prime}=\left(t_{1}^{\prime}, t_{2}^{\prime}, t_{3}^{\prime}\right)$.
1. If $\left(t_{1}+2 t_{2}+t_{3}\right) / 4>(<)\left(t_{1}^{\prime}+2 t_{2}^{\prime}+t_{3}^{\prime}\right) / 4$, then $t>(<) t^{\prime}$.

2. If $\left(t_{1}+2 t_{2}+t_{3}\right) / 4=\left(t_{1}^{\prime}+2 t_{2}^{\prime}+t_{3}^{\prime}\right) / 4$, then $t_{2}$ and $t_{2}^{\prime}$ is compared. If $t_{2}>(<) t_{2}^{\prime}$, then $t>(<) t^{\prime}$.

3. If $t_{2}=t_{2}^{\prime}$, then the spreads of two TFNs are compared. If $t_{3}-t_{1}>(<) t_{3}^{\prime}-t_{1}^{\prime}$, then $t>(<) t^{\prime}$.

Max operation: Lei (Lei, 2010) defined a membership function $\mu_{t \vee t^{\prime}}(z)$ of $t \vee t^{\prime}: \mu_{t \vee t^{\prime}}(z)=\sup _{z=x \vee y} \min \left(\mu_{t}(x), \mu_{t^{\prime}}(y)\right)$. In the literature, the max of two TFNs is approximated with the criterion: If $t>t^{\prime}$, then $t \vee t^{\prime}=t$; otherwise $t \vee t^{\prime}=t^{\prime}$. In this study, the max of two TFNs is approximated with the criterion: If $t>t^{\prime}$, then $t \vee t^{\prime}=t$; otherwise $t \vee t^{\prime}=t^{\prime}$.

\section{IABC for FJSP with fuzzy processing time}

\subsection{ABC algorithm}

Artificial bee colony (ABC) algorithm is a population-based meta-heuristic proposed by Karaboga (Akay \& Karaboga, 2012; Karaboga \& Akay, 2009). ABC is inspired from the foraging behavior of a bee colony. There are three kinds of bees, namely, employed bees, onlooker bees and scout bees in ABC algorithm. A bee that is currently exploiting a food source is called an employed bee. A bee waiting in the hive for making decision to choose a food source is named as an onlooker. A bee carrying out a random search for a new food source is called a scout. Each solution to the problem under consideration is called a food source, whereas the fitness of the solution corresponds to the amount of nectar of the associated food source. The main steps of the basic ABC algorithm are shown.

1. Initialization of the parameters and population:

The parameters of $\mathrm{ABC}$ are the number of food sources ( $\mathrm{SN}$ ), the number of trials after which a food source is to be abandoned (limit) and the termination criterion. The number of food sources is equal to the number of employed bees or onlooker bees. The initialization of population is to fill the population with $\mathrm{SN}$ number of randomly generated food sources, $n$-dimensional realvalued vectors.

Let $X_{i}=\left\{x_{i 1}, x_{i 2}, \ldots, x_{i n}\right\}$ represent the $i$ th food source in the population. The food sources are generated as follows:

$$
x_{i j}=L B_{j}+\left(U B_{j}-L B_{j}\right) \times r j=1,2, \ldots, n, i=1,2, \ldots, S N
$$

where $r$ is a uniform random number in the range $[0,1] ; L B_{j}$ and $U B_{j}$ are the lower and upper bounds for the dimension $j$, respectively. The food sources are randomly assigned to employed bees and the corresponding finesses are evaluated.

2. Employed bee phase: 
In this phase, each employed bee $X_{i}$ generates a new food source $X_{n e w}$ in the neighborhood of its present position as follows:

$$
x_{n e w(j)}=x_{i j}+\left(x_{i j}-x_{k j}\right) \times r^{\prime}
$$

where $k \in\{1,2, \ldots, S N\} \wedge k \neq i$ and $j \in\{1,2, \ldots, n\}$ are randomly chosen indexes. $r^{\prime}$ is a uniformly distributed real number in [-1, 1]. $X_{n e w}$ will be compared to $X_{i}$. If the fitness of $X_{n e w}$ is equal to or better than that of $X_{i}, X_{n e w}$ will replace $X_{i}$ as a new food source; otherwise $X_{i}$ is retained.

3. Onlooker bee phase:

An onlooker bee evaluates all the employed bees and selects a food source $X_{i}$ depending on its probability value $p_{i}$ calculated by the following expression:

$$
p_{i}=\frac{f_{i}}{\sum_{i=1}^{S N} f_{i}}
$$

where $f_{i}$ is the nectar amount or the fitness value of the $i$ th food source $X_{i}$. The higher the $f_{i}$ is, the more ability that the $i$ th food source is selected.

Once the food source $X_{i}$ is selected, the onlooker bee will execute the update $X_{i}$ using equation (9). If the new food source has equal or better fitness value than $X_{i}$, the new food source will replace $X_{i}$ as a new member in the population.

\section{Scout bee phase}

If a food source $X_{i}$ can not be improved through a predetermined number of trials limit, the food source is to be abandoned and the corresponding employed bee becomes a scout. The scout produces a new food source randomly as follows:

$$
x_{i j}=L B_{j}+\left(U B_{j}-L B_{j}\right) \times r \text { for } j=1,2, \ldots, n
$$

where $r$ is a uniform random number in the range $[0,1]$. 5. Repeat steps 2)-4) until the termination criterion is satisfied.

\subsection{Solution representation}

In the IABC algorithm, each employed bee or onlooker bee is put on a solution. For example, a solution of 4-job, 4-machine remanufacturing instance is shown in Fig. 1. Each element in solution includes three values, job number, operation number and processing machine number. The first element, $(3,1,2)$, means that the first operation of job 3 is processed on machine 2 . The element number is the total operation number of all jobs. In this coding rule, the order of operation sequence and machine assignment are consistent.

Table 1 shows the fuzzy processing time of each job on corresponding machines. For example, the first fuzzy number $(2$, $4,8)$ means that the most probable processing time of operation $O_{11}$ on machine $M_{1}$ is 4 , while the range of the processing time is from 2 to 8 . It means that the actual processing time of operation $\underline{O}_{11}$ on machine $M_{1}$ in shop floor should be one value from 2 to

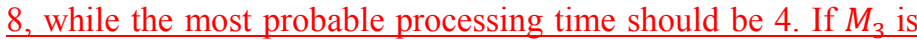
selected for processing operation $O_{11}$, the most probable processing time will be 5 and the range of processing time is from 4 to 7 .

The solution in Fig. 1 can be decoded from left to right. The operations on the same machine are processed based on the order appearance in operation sequence. For example, the third element, $(4,1,4)$ and the fifth element, $(3,2,4)$ in Fig. 1 have the same processing machine $M_{4}$. The operation, $(4,1)$ will be processed first on machine $M_{4}$. The machine $M_{4}$ is available for operation $(3,2)$ when the operation $(4,1)$ is completed. In this way, the solution can be decoded to a schedule. The processing orders on all machines are $M_{1}=O_{4,2}, O_{3,3}, O_{2,3}$, $M_{2}=O_{3,1}, O_{2,1}, O_{1,3}, M_{3}=O_{1,1}, O_{1,2}, O_{2,2}$ and $M_{4}=O_{4,1}, O_{3,2}, O_{4,3}$. The fuzzy completion time can be computed and the value is (17, 27, 31). The Gantt chart with fuzzy processing time is called fuzzy Gantt chart. Fig. 2 shows the fuzzy Gantt chart of the solution in Fig. 1. For the same operation, the TFN under the line is the fuzzy start time while the TFN above the line means the fuzzy completion time.

To verify the fuzzy schedule is feasible in actual remanufacturing processing shop floor, Fig. 3 shows a Gantt chart with the actual processing time $(6,9,5 ; 6,6,4 ; 7,10,2 ; 2,6,4)$ of all operations $\left(\mathrm{O}_{11}, \mathrm{O}_{12}, \mathrm{O}_{13} ; \mathrm{O}_{21}, \mathrm{O}_{22}, \mathrm{O}_{23} ; \mathrm{O}_{31}, \mathrm{O}_{32}, \mathrm{O}_{33} ; \mathrm{O}_{41}\right.$, $\left.\mathrm{O}_{42}, \mathrm{O}_{43}\right)$. These processing time values are recorded in remanufacturing shop floor and all values are in the intervals of the corresponding fuzzy processing times that are shown in Table 1. For the same operation sequence in Table 1, the actual makespan in remanufacturing shop floor is 25 while the fuzzy maximum completion time in Fig. 2 is $(17,27,31)$. The actual makespan 25 is in the interval of the fuzzy completion time. Hence, the fuzzy schedule is feasible in real-life shop floor and the fuzzy Gantt schedule can supply high quality decision support for the practical remanufacturing engineering.

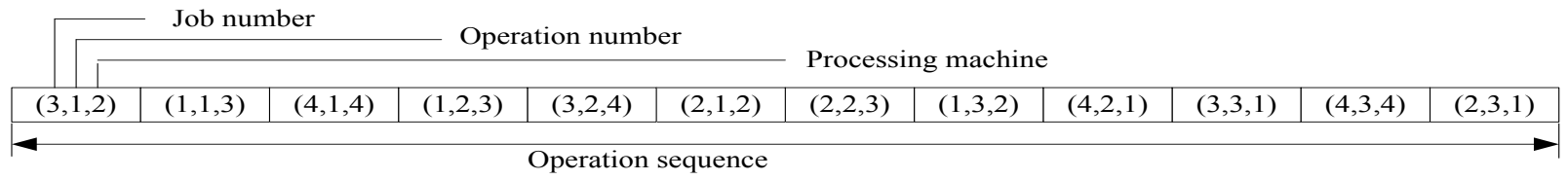

Fig. 1 Illustration of a solution

Table 1 Fuzzy processing time

Job

Operation

Machine

$M_{1}$

$M_{2}$

$M_{3}$

$M_{4}$ 


\begin{tabular}{|c|c|c|c|c|c|}
\hline \multirow[t]{3}{*}{1} & $O_{11}$ & $(2,4,8)$ & - & $(4,5,7)$ & - \\
\hline & $O_{12}$ & $(6,8,12)$ & $(5,8,10)$ & $(6,7,10)$ & $(4,7,9)$ \\
\hline & $O_{13}$ & $(8,9,12)$ & $(3,4,5)$ & - & - \\
\hline \multirow[t]{3}{*}{2} & $O_{21}$ & & $(5,9,10)$ & & $(7,9,12)$ \\
\hline & $O_{22}$ & $(2,4,5)$ & & $(4,7,8)$ & $(1,2,4)$ \\
\hline & $O_{23}$ & $(3,5,6)$ & $(1,3,4)$ & $(1,2,5)$ & \\
\hline \multirow[t]{3}{*}{3} & $O_{31}$ & - & $(5,6,7)$ & - & $(3,5,6)$ \\
\hline & $O_{32}$ & $(1,2,3)$ & $(6,8,10)$ & $(5,9,11)$ & $(9,10,14)$ \\
\hline & $O_{33}$ & $(1,3,4)$ & - & $(4,6,8)$ & - \\
\hline \multirow[t]{3}{*}{4} & $O_{41}$ & - & $(5,7,9)$ & $(1,2,5)$ & $(1,2,3)$ \\
\hline & $O_{42}$ & $(5,6,9)$ & $(4,5,7)$ & $(3,5,6)$ & $(1,2,3)$ \\
\hline & $O_{43}$ & $(7,8,11)$ & - & - & $(1,3,4)$ \\
\hline
\end{tabular}

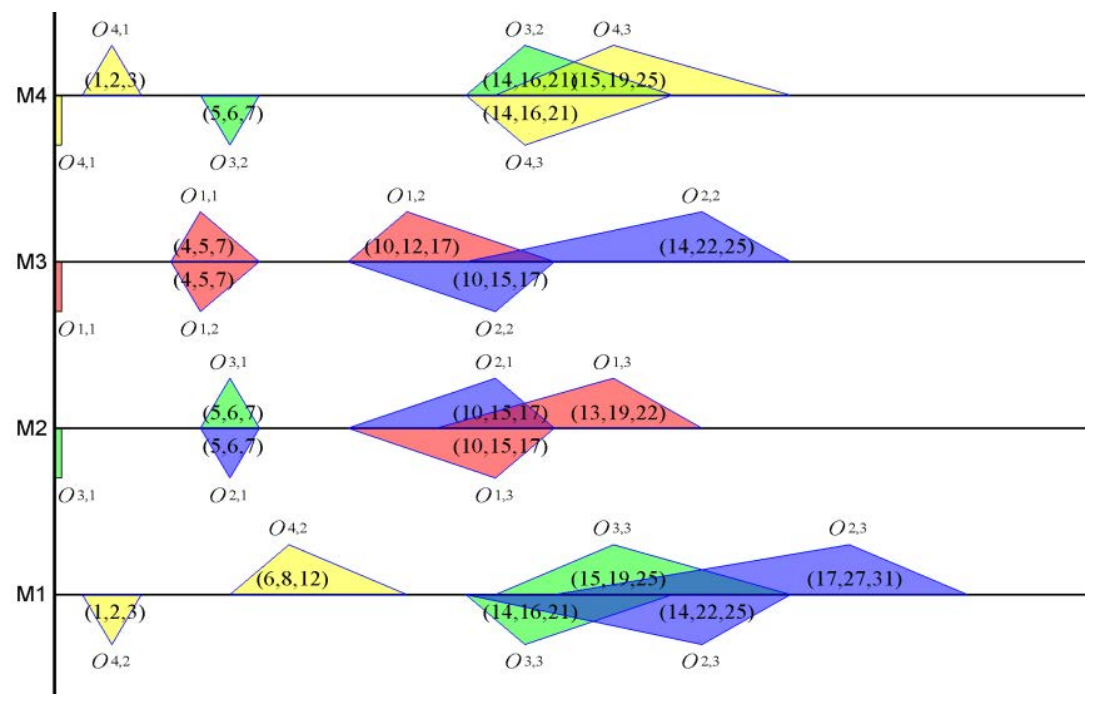

Fig. 2 The fuzzy Gantt chart of the example

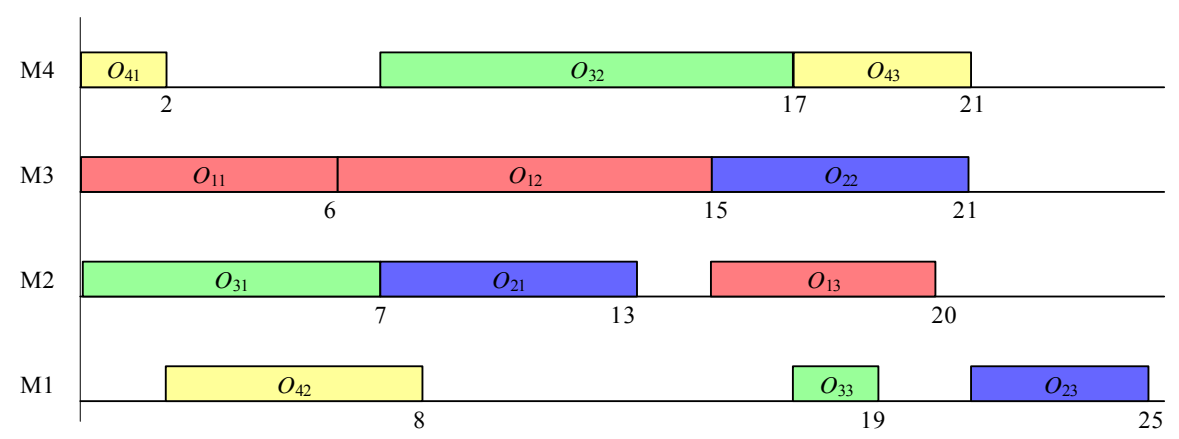

Fig. 3 Gantt chart based on actual processing time 


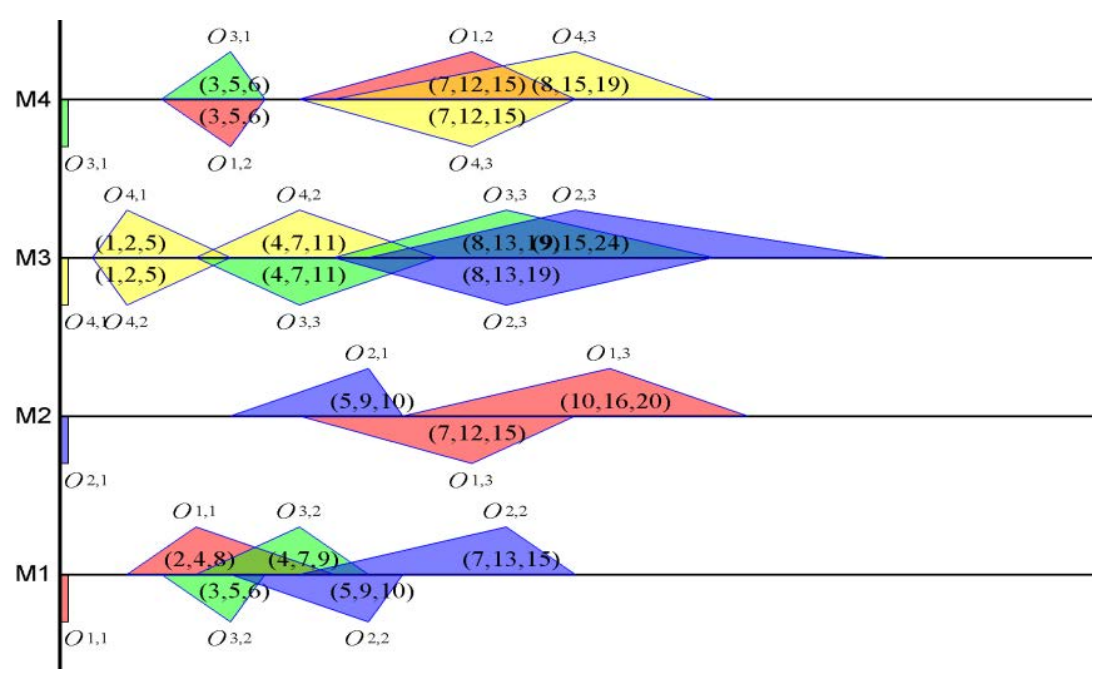

Fig. 4 The fuzzy Gantt chart by MinEnd heuristic

\subsection{MinEnd heuristic}

The quality of initial population often affects the convergence of meta-heuristic for FJSP problem. It is important to generate a good quality initial population. Many heuristic rules are proposed for machine assignment and operation sequencing in FJSP problem, such as, local minimizing processing time (LS) rule, global minimizing processing time rule (GS), most work remaining rule (MReW) and most number of operations remaining (MReO) rule (Pezzella, Morganti \& Ciaschetti, 2008). In this study, we develop a new simple heuristic rule, named MinEnd heuristic, for initializing population. In this rule, the operation sequence is generated randomly. The processing machine is assigned based on the operation order in operation sequence. For each operation, the machine with the minimum fuzzy completion time will be selected to process this operation.

To show the MinEnd heuristic clearly, we take the problem in Table 1 as an example. The solution shown in Fig. 1 is used as operation sequence. The processing machine is assigned based on the MinEnd heuristic. For the first operation $(3,1)$, selectable machines are $M_{2}$ and $M_{4}$. The fuzzy completion time on machine $M_{2}$ is $(5,6,7)$ while the fuzzy completion time on $M_{4}$ is $(3,5,6)$. Based on the fuzzy TFNs ranking criteria, $(5,6,7)$ is larger than $(3,5,6)$. Hence, $M_{4}$ is selected for operation $(3,1)$. The available time of $M_{4}$ for next operation is $(3,5,6)$. The second operation is $(1,1)$. The fuzzy completion on selectable machine $M_{1}$ and $M_{3}$ are $(2,4,8)$ and $(4,5,7)$, respectively. Machine $M_{1}$ is selected and the available time becomes $(2,4,8)$. For third operation $(4,1)$, the selectable machine are $M_{2}, M_{3}$ and $M_{4}$. The fuzzy completion time on $M_{2}$ and $M_{3}$ are $(5,7,9)$ and $(1,2,5)$. Because the available time of $M_{4}$ is $(3,5,6)$, the fuzzy completion time on $M_{4}$ is the addition of $(3,5,6)$ and $(1,2,3)$. Based on the TFNs addition operation, the fuzzy completion time is $(4,7,9)$. Based on the TFNs ranking criteria, $(1,2,5)$ is smaller than $(5,7,9)$ and $(4,7,9)$.
So, $M_{3}$ is selected for operation $(4,1)$ and the available time becomes $(1,2,5)$. All remaining operations can be assigned one processing machine in the same way. The final operation order on each machine are $M_{1}=O_{1,1}, O_{3,2}, O_{2,2}, M_{2}=O_{2,1}, O_{1,3}$, $M_{3}=O_{4,1}, O_{4,2}, O_{3,3}, O_{2,3}$ and $M_{4}=O_{3,1}, O_{1,2}, O_{4,3}$. The Gantt chart of fuzzy completion time is shown in Fig. 4. Compare to the result $(17,27,31)$ in Fig. 2, MinEnd heuristic gets better fuzzy completion time $(9,15,24)$.

\subsection{Employed bee phase}

In this phase, employed bee $X_{i}$ generates a new food source $X_{n e w}$. If the fitness of $X_{n e w}$ is equal to or better than that of $X_{i}$, $X_{n e w}$ will replace $X_{i}$ as a new food source; otherwise, $X_{i}$ is retained. To adapt FJSP with fuzzy processing time and encoding rule, the procedure for new food source is shown as follows:

Procedure: Generating new food source

If $(\mathrm{r} 1<\mathrm{P} 1) / / \mathrm{r} 1$ is a random value in $[0,1], \mathrm{P} 1$ is the probability to generate new food source

Select two employed bee $X_{p}$ and $X_{q}, X_{p} \neq X_{q} \neq X_{i}$.

If $(\mathrm{r} 2<\mathrm{P} 2)$

If the fitness of $X_{p}$ is better than that of $X_{q}$,

$$
X_{j}=X_{p}
$$

Else

$$
X_{j}=X_{q} .
$$

Else

If the fitness of $X_{p}$ is better than that of $X_{q}$,

Else

$$
X_{j}=X_{q}
$$

$$
X_{j}=X_{p} .
$$

For $\mathrm{k}=1$ to toper $/ /$ toper is the total operation number If $(\mathrm{r} 3<\mathrm{P} 3)$

$$
\begin{gathered}
X_{\text {new }}^{k}=X_{j}^{k} \\
\text { Else } \\
X_{\text {new }}^{k}=X_{i}^{k}
\end{gathered}
$$


Repair $X_{n e w}$ to make sure the operations of the same job Else can satisfy the processing precedence.

For $\mathrm{k}=1$ to toper $/ /$ toper is the total operation number If $(\mathrm{r} 4<\mathrm{P} 4)$

If current machine has minimum processing time

Select another machine randomly for $X_{i}^{k}$ Else

Select minimum processing time machine for $X_{i}^{k}$ Else

Select two operations $X_{i}^{a}$ and $X_{i}^{b}, a<b$.

If $X_{i}^{a}$ and $X_{i}^{b}$ are different jobs' operations

Insert $X_{i}^{a}$ at $X_{i}^{b}$ position.

Repair $X_{n e w}$ to make sure the operations of the same job

End can satisfy the processing precedence.

The repair operator for $X_{n e w}$ is to make sure the same job's operations can be processed as sequential steps of operations. The detail procedure of repair operator is shown as follows:

Procedure: Repair operator for $X_{\text {new }}$

For $\mathrm{k} 1=1$ to toper $/ /$ toper is the total operation number of all jobs

For $\mathrm{k} 2=\mathrm{k} 1-1$ to 0

Two operations $O_{i 1, h 1}$ and $O_{i 2, h 2}$ are selected.

If $i 1=i 2$ and $h 1<h 2$

Exchange the positions of operations $O_{i 1, h 1}$ and $O_{i 2, h 2}$ Else

Continue

End

End

\subsection{Onlooker phase}

In onlooker bee phase, the fitnesses of all the employed bees are evaluated. A food source $X_{i}$ is selected depending on its probability value $p_{i}$ calculated by expression (10). The procedure to select a food source is shown as follows:

Procedure: Select a food source

Select two employed bee $X_{p}$ and $X_{q}, X_{p} \neq X_{q}$

If $(\mathrm{r} 2<\mathrm{P} 2) / / \mathrm{r} 2$ is a random in $[0,1]$

If the fitness of $X_{p}$ is better than that of $X_{q}$

$$
\begin{aligned}
& X_{i}=X_{p} \\
& X_{i}=X_{q}
\end{aligned}
$$

Else

Else

If the fitness of $X_{p}$ is worse than that of $X_{q}$,

$$
\begin{aligned}
X_{i} & =X_{p} \\
\text { Else } & \\
X_{i} & =X_{q}
\end{aligned}
$$

End

Once the food source $X_{i}$ is selected, the onlooker bee will update $X_{i}$ using the Procedure in Section 4.3. If the new food source $X_{n e w}$ has equal or better fitness value than $X_{i}$, the new food source $X_{n e w}$ will replace $X_{i}$ as a new member in the population.

\subsection{Scout bee phase}

If a food source $X_{i}$ cannot be improved through a predetermined number of trials Limit, the food source is to be abandoned and the corresponding employed bee becomes a scout. A new food source will be generated randomly.

\subsection{Procedure of IABC}

In the IABC algorithm, the proposed MinEnd heuristic, GS heuristic rule, and random rule are used to initial population. In the procedure to generate new food source, changing processing machine operator and operation inserting operator are employed for exploitation search. Better or worse food source selection and scout bee operator are used for exploration search. Based on the special design above, the procedure of IABC algorithm is as follows:

Procedure: IABC algorithm

Step1: Set parameters, employed bee number, onlooker bee number, scout bee number.

Step2: Initialize population using MinEnd heuristic, global minimizing processing time rule and random rule.

Step3: Perform employed bee phase.

Step4: Perform onlooker bee phase.

Step5: Update the best solution.

Step6: If Limit is met, perform scout bee phase

Step7: If the stop criterion is not satisfied, go to Step 3; else, output the best solution.

\section{Experiment evaluation and comparisons}

\subsection{Experimental setup}

To evaluate the performance of proposed IABC algorithm for minimizing the maximum fuzzy completion time and the maximum fuzzy machine workload criteria, experiments and comparisons are conducted. Two sets of instances are evaluated in this study. Set one consists of five FJSP cases with fuzzy processing time. The sizes are ranging from 10-jobs, 10machines and 40-operations to 15-jobs, 10-machines and 80operations. Set two includes eight instances from one remanufacturing enterprise and the fuzzy processing time are generated based on the historical data of the corresponding 
operations and the experiences of remanufacturing engineers. The size is from 5-jobs, 4-machines and 23-operations to 20jobs, 15-machines and 355-operations. The proposed IABC algorithm is coded in $\mathrm{C}++$ and run on Intel $2.40 \mathrm{GHz} \mathrm{PC}$ with 2 GB memory. The parameters are set based on our previous researched and compared algorithms as follows: employed bee 50; onlooker bee 100 , scout bee 20 , limit $50, \mathrm{P} 1=0.8, \mathrm{P} 2=0.95$, $\mathrm{P} 3=0.2$ and $\mathrm{P} 4=0.5$. For instances in set one and the previous four instances in set two, the generation is set to 1000 . For the last four instances in set two, the generation is set to 4000 because the problem size of these four instances is larger than that of other instances. All experiments are carried out with 30 replications.

In IABC algorithm, the population is generated by MinEnd heuristic, GS heuristic and random rule. Six groups with different number of solutions initialized by MinEnd and GS heuristics are used to test results and convergence performance. MinEnd and GS heuristics are for maximum fuzzy completion time objective and maximum fuzzy machine workload objective. In this test, MinEnd heuristic and GS heuristic initialize the same number solutions for maximum fuzzy completion time objective of instance Reman 3. In six groups, the solutions initialized by MinEnd and GS heuristics are set to $(2.5 \%, 2.5 \%),(5 \%, 5 \%)$, $(10 \%, 10 \%),(20 \%, 20 \%),(30 \%, 30 \%),(40 \%, 40 \%)$. Average results and convergence curves by random initialization (without MinEnd and GS heuristics) are also presented. The average results in 30 runs for instance Reman 3 are computed for the first ranking criterion of TNF. The convergence curves and results of six groups and random initializing are shown in Fig. 5. It can be seen clearly that all settings with MinEnd and GS heuristics have better results than by random initialization and the group with $(5 \%, 5 \%)$ setting has the best convergence curve and result. Hence, 5\% solutions are initialized by MinEnd heuristic, 5\% solutions are initialized by GS rule, and $90 \%$ solutions are initialized randomly.

\subsection{Testing MinEnd heuristic}

To test MinEnd heuristic performance, five cases in set one are evaluated by MinEnd heuristic, global minimizing processing time rule (GS), local minimizing processing time (LS), most work remaining $(\mathrm{MReW})$, most number of operations remaining (MReO) and random heuristic rules. The maximum fuzzy completion time results are shown in Table 2 while the maximum fuzzy machine workload results are shown in Table 3. For the two objectives, best values, the average of the expected values and worst values in 30 runs are counted.

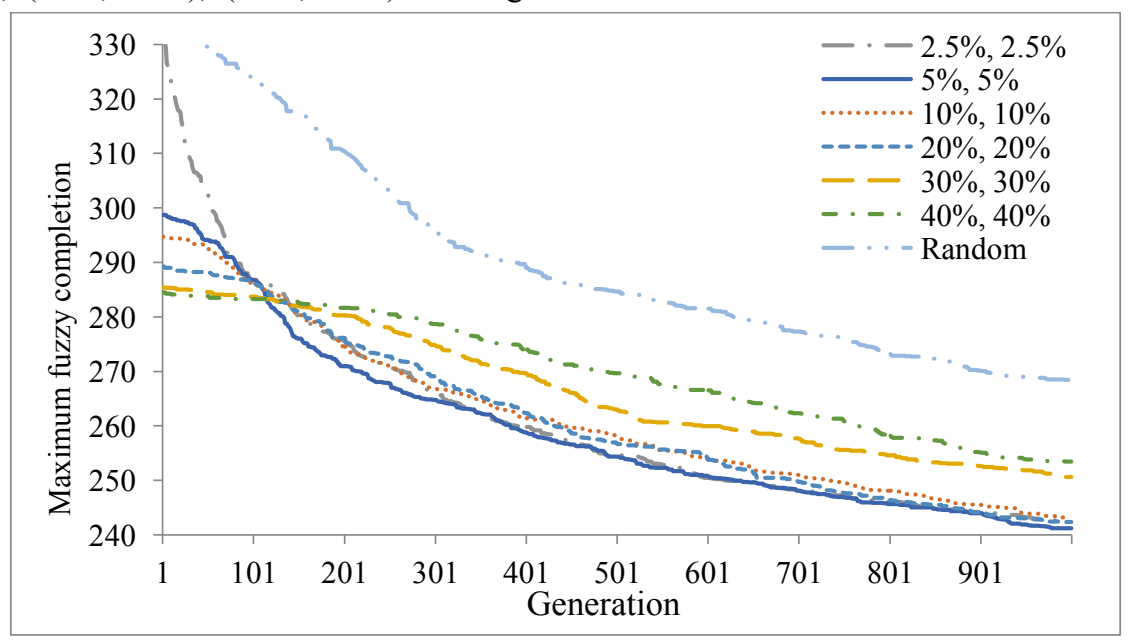

Fig. 5 The convergence curves of six group settings and random initialization

Table 2 Maximum fuzzy completion time of five cases by six heuristics

\begin{tabular}{|c|c|c|c|c|c|c|c|c|c|c|}
\hline \multirow{2}{*}{$\frac{\text { Instance }}{\text { Case1 }}$} & \multirow{2}{*}{$\frac{\text { Algorithm }}{\text { MinEnd }}$} & \multicolumn{3}{|c|}{ Average value } & \multicolumn{3}{|c|}{ Best value } & \multicolumn{3}{|c|}{ Worst value } \\
\hline & & 45.6 & 61.9 & 81.0 & 42 & 53 & 69 & 51 & 73 & 94 \\
\hline & GS & 52.0 & 74.3 & 96.2 & 38 & 53 & 67 & 76 & 113 & 150 \\
\hline & LS & 49.4 & 71.2 & 90.9 & 22 & 46 & 58 & 63 & 92 & 125 \\
\hline & $\mathrm{MReO}$ & 59.7 & 88.8 & 117.0 & 54 & 79 & 103 & 75 & 110 & 143 \\
\hline & Random & 59.2 & 88.0 & 116.2 & 49 & 75 & 102 & 69 & 102 & 138 \\
\hline & GS & 80.7 & 108.3 & 138.5 & 50 & 69 & 90 & 108 & 147 & 189 \\
\hline & LS & 81.5 & 109.9 & 140.3 & 57 & 77 & 97 & 115 & 154 & 196 \\
\hline & MReW & 98.4 & 132.6 & 168.8 & 89 & 118 & 151 & 114 & 152 & 195 \\
\hline & $\mathrm{MReO}$ & 102.9 & 139.3 & 177.9 & 89 & 118 & 151 & 127 & 169 & 216 \\
\hline & Random & 99.0 & 134.4 & 171.6 & 89 & 118 & 151 & 131 & 178 & 229 \\
\hline
\end{tabular}




\begin{tabular}{|c|c|c|c|c|c|c|c|c|c|c|}
\hline \multirow[t]{6}{*}{ Case3 } & MinEnd & 46.1 & 65.9 & 85.6 & 40 & 57 & 72 & 54 & 79 & 101 \\
\hline & GS & 72.1 & 97.7 & 125.1 & 47 & 65 & 87 & 90 & 123 & 156 \\
\hline & LS & 77.3 & 105.6 & 135.7 & 58 & 76 & 97 & 98 & 132 & 171 \\
\hline & MReW & 88.3 & 117.9 & 151.5 & 68 & 91 & 117 & 109 & 142 & 185 \\
\hline & MReO & 83.3 & 111.7 & 143.7 & 72 & 96 & 122 & 128 & 167 & 217 \\
\hline & Random & 85.5 & 114.1 & 146.9 & 71 & 97 & 126 & 116 & 151 & 193 \\
\hline \multirow[t]{6}{*}{ Case4 } & MinEnd & 34.9 & 51.9 & 72.2 & 28 & 45 & 62 & 39 & 59 & 88 \\
\hline & GS & 55.9 & 79.4 & 105.6 & 36 & 60 & 81 & 81 & 118 & 158 \\
\hline & LS & 54.7 & 78.1 & 103.1 & 39 & 57 & 74 & 78 & 108 & 141 \\
\hline & MReW & 64.4 & 87.7 & 113.4 & 54 & 70 & 90 & 86 & 126 & 163 \\
\hline & $\mathrm{MReO}$ & 61.8 & 85.6 & 110.6 & 52 & 70 & 90 & 70 & 100 & 129 \\
\hline & Random & 67.7 & 93.7 & 121.3 & 48 & 70 & 90 & 78 & 110 & 141 \\
\hline \multirow[t]{6}{*}{ Case5 } & MinEnd & 53.7 & 78.5 & 108.2 & 45 & 68 & 94 & 61 & 93 & 126 \\
\hline & GS & 80.9 & 113.5 & 150.4 & 53 & 83 & 113 & 103 & 142 & 194 \\
\hline & LS & 81.2 & 111.3 & 146.8 & 90 & 73 & 100 & 114 & 158 & 204 \\
\hline & MReW & 92.1 & 129.1 & 170.8 & 76 & 111 & 147 & 104 & 144 & 188 \\
\hline & $\mathrm{MReO}$ & 95.5 & 134.1 & 177.5 & 85 & 114 & 157 & 113 & 155 & 207 \\
\hline & Random & 94.4 & 132.7 & 174.7 & 83 & 114 & 149 & 134 & 190 & 247 \\
\hline
\end{tabular}

Table 3 Maximum fuzzy machine workload of five cases by six heuristics

\begin{tabular}{|c|c|c|c|c|c|c|c|c|c|c|}
\hline \multirow{2}{*}{$\frac{\text { Instance }}{\text { Case1 }}$} & \multirow{2}{*}{$\frac{\text { Algorithm }}{\text { MinEnd }}$} & \multicolumn{3}{|c|}{ Average value } & \multicolumn{3}{|c|}{ Best value } & \multicolumn{3}{|c|}{ Worst value } \\
\hline & & 23.0 & 34.2 & 45.9 & 21 & 30 & 40 & 26 & 41 & 54 \\
\hline & GS & 20.9 & 30.6 & 40.9 & 19 & 27 & 40 & 26 & 33 & 42 \\
\hline & LS & 33.0 & 50.0 & 64.0 & 33 & 50 & 64 & 33 & 50 & 64 \\
\hline & MReW & 45.0 & 66.0 & 85.4 & 30 & 44 & 57 & 66 & 92 & 114 \\
\hline & $\mathrm{MReO}$ & 42.3 & 62.6 & 81.3 & 27 & 41 & 55 & 65 & 102 & 132 \\
\hline & Random & 41.0 & 60.1 & 78.3 & 27 & 39 & 51 & 60 & 81 & 106 \\
\hline \multirow[t]{6}{*}{ Case2 } & MinEnd & 36.6 & 50.2 & 65.1 & 31 & 42 & 53 & 46 & 61 & 80 \\
\hline & GS & 32.1 & 44.5 & 57.4 & 28 & 40 & 50 & 33 & 47 & 65 \\
\hline & LS & 54.0 & 75.0 & 96.0 & 54 & 75 & 96 & 54 & 75 & 96 \\
\hline & MReW & 61.3 & 83.8 & 108.6 & 41 & 59 & 75 & 94 & 130 & 167 \\
\hline & $\mathrm{MReO}$ & 69.2 & 94.6 & 122.0 & 44 & 56 & 77 & 109 & 147 & 188 \\
\hline & Random & 65.0 & 88.9 & 113.9 & 42 & 60 & 78 & 93 & 129 & 165 \\
\hline \multirow[t]{6}{*}{ Case3 } & MinEnd & 36.4 & 51.4 & 66.6 & 27 & 42 & 56 & 40 & 61 & 78 \\
\hline & GS & 32.1 & 45.0 & 59.4 & 32 & 44 & 55 & 34 & 49 & 66 \\
\hline & LS & 49.0 & 72.0 & 89.0 & 49 & 72 & 89 & 49 & 72 & 89 \\
\hline & MReW & 63.5 & 88.9 & 115.2 & 48 & 66 & 85 & 93 & 130 & 164 \\
\hline & $\mathrm{MReO}$ & 67.1 & 94.5 & 123.2 & 39 & 58 & 77 & 95 & 131 & 172 \\
\hline & Random & 61.9 & 86.7 & 112.3 & 41 & 62 & 83 & 90 & 122 & 161 \\
\hline \multirow[t]{6}{*}{ Case4 } & MinEnd & 27.7 & 39.7 & 55.1 & 25 & 35 & 45 & 35 & 46 & 61 \\
\hline & GS & 23.9 & 34.9 & 48.4 & 23 & 33 & 45 & 28 & 38 & 52 \\
\hline & LS & 25.0 & 39.0 & 57.0 & 25 & 39 & 57 & 25 & 39 & 57 \\
\hline & MReW & 46.9 & 66.6 & 91.6 & 34 & 48 & 69 & 69 & 97 & 138 \\
\hline & $\mathrm{MReO}$ & 45.0 & 65.3 & 90.6 & 28 & 42 & 60 & 71 & 98 & 133 \\
\hline & Random & 41.8 & 60.2 & 82.5 & 30 & 42 & 61 & 60 & 83 & 110 \\
\hline \multirow[t]{6}{*}{ Case5 } & MinEnd & 45.2 & 64.9 & 88.7 & 42 & 60 & 80 & 50 & 73 & 97 \\
\hline & GS & 41.1 & 59.4 & 80.0 & 38 & 57 & 80 & 45 & 64 & 80 \\
\hline & LS & 52.0 & 76.0 & 109.0 & 52 & 76 & 109 & 52 & 76 & 109 \\
\hline & MReW & 80.9 & 114.5 & 154.0 & 65 & 88 & 118 & 110 & 155 & 206 \\
\hline & $\mathrm{MReO}$ & 80.9 & 113.2 & 151.4 & 55 & 86 & 119 & 105 & 141 & 189 \\
\hline & Random & 83.4 & 118.3 & 158.5 & 60 & 85 & 114 & 145 & 201 & 268 \\
\hline
\end{tabular}

Compared to random rule, $\mathrm{MReW}$ and $\mathrm{MReO}$ rules cannot improve maximum fuzzy completion time and maximum fuzzy machine workload results. MinEnd, GS and LS heuristic rules can yield higher quality results than $\mathrm{MReW}, \mathrm{MReO}$ and random rules. Among the six heuristics, MinEnd can find the best maximum fuzzy completion time results for all five cases except the best value of case1. MinEnd heuristic get the best value $(42,53,69)$ for case 1 while LS heuristic rule obtains the best 
value $(22,46,58)$. GS rule can find the maximum fuzzy completion time results second only to MinEnd heuristic. For maximum fuzzy machine workload objective, GS heuristic rule obtains the best results for all five cases except the best value of case 3 . GS finds the best value $(32,44,55)$ for case 3 while MinEnd heuristic finds the best value $(27,42,56)$. MinEnd heuristic can get the maximum fuzzy machine workload results second only to the GS rule. To show the best results clearly, the best results data in Table 2 and Table 3 are in bold. Considering the two objectives, MinEnd and GS are two effective heuristic rules for FJSP with fuzzy processing time.

\subsection{Maximum fuzzy completion time objective}

For the five cases in set one, IABC algorithm is compared to six existing algorithms, EDA (Wand \& Wang, 2013), HABC (Wang \& Zhou, 2013), CGA (Lei, 2010), DIGA (Lei, 2012), PEGA (Pezzella, Morganti \& Ciaschetti, 2008) and PSO+SA (Xia \& $\mathrm{Wu}, 2005)$. The results of average, best and worst values in 30 runs are shown in Table 4. The average CPU times of all the compared algorithms are listed in Table 5. It can be seen from Table 4 that the proposed IABC algorithm performs better than EDA, HABC, CGA, DIGA, PEGA and PSO+SA algorithms. For five cases, IABC algorithm can obtain better average results and best values than those of the six compared algorithms. In 30 runs, IABC can find minimum worst values for case 1 , case 2 case 3 and case 4. EDA algorithm finds minimum worst value for case 5 . The best solution obtained by IABC for case 1 is $(19,28$, 39) and the Gantt chart of the best maximum fuzzy completion time is illustrated in Fig.6. Compared to the six existing algorithms, IABC has the minimum average CPU time. For case 1 to case 4 , the average time of IABC is less than 1.5 seconds. For the largest case, case 5, the average CPU time is just 2.41 seconds. Although the CPU frequencies are different among seven algorithms, we can conclude that the proposed IABC algorithm is the most efficient one.

To further test the performance of the IABC algorithm, the eight remanufacturing instances in set two are solved. The average, best and worst values by IABC algorithm and six heuristics are shown in Table 6 . It can be seen from Table 6 that MinEnd heuristic obtains better results than other five heuristics. IABC can improve MinEnd heuristic's results obviously for all instances as shown in Table 4 and Table 6. IABC can improve the average results by MinEnd more than 30\% for all instances. To show the scheduling results more clearly for eight instances in set two, Fig.7 illustrates the best solution's $(26,38,54)$ fuzzy Gantt chart of instance Reman 2 for maximum fuzzy completion time objective. In addition, the average CPU time and generation for eight instances in set two are shown in Table 7. It can be seen from Table 7 that average CPU time for 1000 generations is less than 3.5 seconds for instance Reman 1 to Reman 4. For instance Reman 5 and Reman 6, the average CPU time is more than 30 seconds. The reason is that the instances become larger and the generation increases from 1000 to 4000 . The instance sizes of Reman 7 and Reman 8 are 20-jobs, 10-machines, 308-operations and 20-jobs, 15-machines, 355-operations. The average CPU time is 82.99 seconds for Reman 7 and 102.77 seconds for Reman8. Considering the results and average CPU times, IABC algorithm is effective for eight remanufacturing instances with maximum fuzzy completion time objective.

To show the convergence of IABC algorithm, Fig. 8 shows the convergence curves of three ranking criteria results by IABC for case 5 and Reman 8. For the same value of the first ranking criterion, the values of the second and the third ranking criteria may become larger or smaller to show the change of results. For the same values of the first and second ranking criteria, the third ranking criterion may become larger or smaller to show the change of results. Hence, the first ranking criterion is nonincreasing for two instances. The second and third ranking criteria may increase or decrease while the third ranking criterion has larger fluctuations than the second one. In summary, IABC algorithm is effect for fuzzy maximum completion time objective of FJSP with fuzzy processing time.

In summary, IABC can obtain better fuzzy maximum completion time results than those by compared six algorithms for five benchmark cases in set one. For eight remanufacturing instances in set two, this study is the first to solve them by intelligent computation algorithm. The results by IABC algorithm are compared to several simple heuristics and MinEnd heuristic proposed in this study. The comparisons and discussions show that the IABC algorithm have better competitiveness than simple heuristics. The results for the remanufacturing instances has been verified in real-life shop floor and the IABC algorithm has been integrated into rescheduling system for fuzzy maximum completion time objective.

For the fuzzy maximum completion time objective, IABC algorithm obtain high quality scheduling solutions which can guarantee the effectiveness of real-life remanufacturing management. The processing time and the maximum completion time are presented using triangular fuzzy number. The scheduling solutions are flexible to adapt to the feature of remanufacturing engineering. It can improve the controllability of remanufacturing

Table 4 Maximum fuzzy completion time by seven algorithms for five cases

\begin{tabular}{|c|c|c|c|c|c|c|c|c|c|c|}
\hline \multirow{2}{*}{$\frac{\text { Instance }}{\text { Case } 1}$} & Algorithm & \multicolumn{3}{|c|}{ Average value } & \multicolumn{3}{|c|}{ Best value } & \multicolumn{3}{|c|}{ Worst value } \\
\hline & IABC & 20.1 & 29.4 & 40.3 & 19 & 28 & 39 & 22 & 30 & 42 \\
\hline & EDA & 20.3 & 30.5 & 41.6 & 20 & 28 & 40 & 22 & 32 & 43 \\
\hline & HABC & 21 & 32 & 43.6 & 19 & 30 & 43 & 23 & 33 & 46 \\
\hline & CGA & 23.1 & 33.1 & 43.4 & 21 & 29 & 41 & 25 & 37 & 47 \\
\hline
\end{tabular}




\begin{tabular}{|c|c|c|c|c|c|c|c|c|c|c|}
\hline & DIGA & 22.5 & 32.7 & 43.3 & 21 & 31 & 40 & 25 & 36 & 48 \\
\hline & PEGA & 25 & 35.1 & 47.2 & 23 & 31 & 42 & 29 & 40 & 50 \\
\hline & $\mathrm{PSO}+\mathrm{SA}$ & 26.2 & 36.9 & 47.7 & 25 & 32 & 40 & 27 & 41 & 54 \\
\hline \multirow[t]{7}{*}{ Case2 } & IABC & 32.3 & 46.2 & 57.3 & 33 & 45 & 58 & 35 & 46 & 57 \\
\hline & EDA & 33.7 & 46.9 & 57.9 & 32 & 46 & 57 & 34 & 48 & 58 \\
\hline & HABC & 33 & 47.8 & 62.2 & 33 & 46 & 58 & 36 & 48 & 65 \\
\hline & CGA & 35 & 47.1 & 60.6 & 32 & 47 & 57 & 38 & 49 & 64 \\
\hline & DIGA & 33.4 & 47.5 & 62.1 & 31 & 47 & 59 & 38 & 50 & 66 \\
\hline & PEGA & 36.9 & 51 & 65.9 & 34 & 45 & 60 & 38 & 55 & 72 \\
\hline & $\mathrm{PSO}+\mathrm{SA}$ & 36.7 & 51.2 & 65.2 & 34 & 45 & 60 & 39 & 54 & 74 \\
\hline \multirow[t]{7}{*}{ Case3 } & IABC & 31.8 & 45.8 & 59.6 & 31 & 45 & 57 & 33 & 47 & 63 \\
\hline & EDA & 32.8 & 47.2 & 62.9 & 31 & 46 & 60 & 34 & 49 & 66 \\
\hline & HABC & 33.9 & 50.8 & 67.3 & 33 & 47 & 64 & 36 & 54 & 70 \\
\hline & CGA & 36.4 & 50.8 & 66 & 34 & 47 & 63 & 38 & 53 & 71 \\
\hline & DIGA & 36.1 & 51.5 & 67.5 & 36 & 47 & 64 & 40 & 55 & 73 \\
\hline & PEGA & 40.6 & 56.4 & 73.3 & 38 & 51 & 66 & 40 & 59 & 77 \\
\hline & $\mathrm{PSO}+\mathrm{SA}$ & 38.6 & 54.4 & 70 & 36 & 51 & 65 & 40 & 57 & 75 \\
\hline \multirow[t]{7}{*}{ Case4 } & IABC & 24.1 & 36.1 & 50.9 & 25 & 34 & 49 & 24 & 38 & 55 \\
\hline & EDA & 24.8 & 37.2 & 51.9 & 21 & 36 & 50 & 24 & 39 & 57 \\
\hline & HABC & 25.5 & 40 & 56.3 & 23 & 38 & 53 & 25 & 44 & 59 \\
\hline & CGA & 27.4 & 40.4 & 55 & 26 & 37 & 51 & 29 & 42 & 59 \\
\hline & DIGA & 29.6 & 42.4 & 56.9 & 28 & 40 & 56 & 30 & 46 & 63 \\
\hline & PEGA & 34.3 & 48.8 & 65.7 & 34 & 46 & 63 & 35 & 50 & 68 \\
\hline & $\mathrm{PSO}+\mathrm{SA}$ & 33.6 & 47.9 & 64.5 & 32 & 45 & 62 & 34 & 49 & 68 \\
\hline \multirow[t]{7}{*}{ Case5 } & IABC & 37.8 & 55.8 & 77.7 & 36 & 54 & 74 & 42 & 59 & 84 \\
\hline & EDA & 38.6 & 56.9 & 78.3 & 36 & 55 & 73 & 40 & 60 & 81 \\
\hline & HABC & - & & & - & - & & - & & - \\
\hline & CGA & 47 & 65.4 & 86 & 42 & 62 & 82 & 49 & 70 & 91 \\
\hline & DIGA & 45.8 & 66.3 & 88.7 & 42 & 63 & 84 & 49 & 71 & 92 \\
\hline & PEGA & 50.3 & 74 & 96.5 & 48 & 68 & 94 & 50 & 74 & 100 \\
\hline & $\mathrm{PSO}+\mathrm{SA}$ & 51.2 & 74.6 & 97.6 & 48 & 72 & 93 & 52 & 73 & 101 \\
\hline
\end{tabular}

Table 5 CPU time of seven algorithms for five cases

\begin{tabular}{lrrrr}
\hline Algorithm & Case1 & Case2 & Case3 & Case4 \\
\hline IABC $^{\mathrm{a}}$ & 1.00 & 1.00 & 1.35 & 1.37 \\
$\mathrm{EDA}^{\mathrm{b}}$ & 3.65 & 3.63 & 4.86 & 4.56 \\
$\mathrm{HABC}^{\mathrm{c}}$ & 9.87 & 10.88 & 14.8 & 13.85 \\
$\mathrm{CGA}^{\mathrm{d}}$ & 8.29 & 8.26 & 10.66 & 10.83 \\
$\mathrm{DIGA}^{\mathrm{d}}$ & 15.36 & 15.57 & 18.87 & 19.02 \\
$\mathrm{PEGA}^{\mathrm{d}}$ & 12.56 & 12.67 & 15.23 & 13.71 \\
PSO+Sa $^{\mathrm{d}}$ & 12.4 & 12.33 & 15.24 & 37.82 \\
\hline
\end{tabular}

Notes: ${ }^{\mathrm{a}} 2.40 \mathrm{GHz} \mathrm{CPU},{ }^{\mathrm{b}} 2.3 \mathrm{GHz} \mathrm{CPU},{ }^{\mathrm{c}} 2.83 \mathrm{GHz} \mathrm{CPU},{ }^{\mathrm{d}} 1.7 \mathrm{GHz} \mathrm{CPU}$

Table 6 Maximum fuzzy completion time by IABC and six heuristics for eight Reman instances

\begin{tabular}{|c|c|c|c|c|c|c|c|c|c|c|}
\hline \multirow{2}{*}{$\begin{array}{l}\text { Instance } \\
\text { Reman } 1\end{array}$} & \multirow{2}{*}{$\begin{array}{l}\text { Algorithm } \\
\text { IABC }\end{array}$} & \multicolumn{3}{|c|}{ Average value } & \multicolumn{3}{|c|}{ Best value } & \multicolumn{3}{|c|}{ Worst value } \\
\hline & & 17.6 & 26.0 & 34.6 & 19 & 26 & 33 & 19 & 26 & 36 \\
\hline & MinEnd & 25.1 & 38.9 & 51.8 & 18 & 30 & 42 & 37 & 52 & 68 \\
\hline & GS & 31.7 & 47.5 & 63.2 & 25 & 36 & 48 & 41 & 61 & 81 \\
\hline & LS & 29.0 & 46.6 & 61.2 & 17 & 34 & 45 & 40 & 61 & 79 \\
\hline & MReW & 29.6 & 47.3 & 64.7 & 20 & 33 & 45 & 58 & 80 & 107 \\
\hline & $\mathrm{MReO}$ & 28.9 & 41.8 & 55.9 & 16 & 30 & 42 & 57 & 76 & 96 \\
\hline & Random & 33.4 & 50.9 & 67.8 & 14 & 30 & 42 & 74 & 96 & 124 \\
\hline \multirow[t]{5}{*}{ Reman 2} & IABC & 24.9 & 40.6 & 56.7 & 26 & 38 & 54 & 26 & 43 & 60 \\
\hline & MinEnd & 37.5 & 61.2 & 84.9 & 31 & 51 & 73 & 48 & 72 & 96 \\
\hline & GS & 53.6 & 83.8 & 116.3 & 44 & 66 & 91 & 73 & 116 & 160 \\
\hline & LS & 59.3 & 95.2 & 134.3 & 47 & 78 & 108 & 69 & 109 & 153 \\
\hline & MReW & 69.1 & 106.7 & 147.2 & 48 & 75 & 107 & 119 & 167 & 228 \\
\hline
\end{tabular}




\begin{tabular}{|c|c|c|c|c|c|c|c|c|c|c|}
\hline & $\mathrm{MReO}$ & 49.9 & 75.5 & 104.8 & 37 & 59 & 80 & 77 & 100 & 140 \\
\hline & Random & 71.6 & 108.6 & 148.7 & 39 & 65 & 97 & 122 & 169 & 223 \\
\hline \multirow[t]{7}{*}{ Reman 3} & IABC & 37.6 & 59.6 & 80.8 & 37 & 59 & 76 & 46 & 61 & 83 \\
\hline & MinEnd & 64.8 & 99.7 & 133.2 & 57 & 89 & 115 & 69 & 110 & 144 \\
\hline & GS & 76.7 & 117.7 & 159.5 & 56 & 91 & 120 & 91 & 133 & 179 \\
\hline & LS & 82.9 & 128.7 & 173.9 & 67 & 101 & 135 & 108 & 160 & 210 \\
\hline & MReW & 94.9 & 144.6 & 194.0 & 61 & 102 & 138 & 142 & 198 & 262 \\
\hline & $\mathrm{MReO}$ & 69.7 & 104.4 & 137.2 & 47 & 83 & 116 & 115 & 146 & 185 \\
\hline & Random & 93.1 & 142.8 & 191.3 & 61 & 99 & 132 & 165 & 223 & 289 \\
\hline \multirow[t]{7}{*}{ Reman 4} & IABC & 33.6 & 50.9 & 70.3 & 34 & 49 & 67 & 35 & 54 & 75 \\
\hline & MinEnd & 53.2 & 81.0 & 111.7 & 38 & 67 & 94 & 63 & 104 & 147 \\
\hline & GS & 67.2 & 103.9 & 141.7 & 58 & 91 & 126 & 94 & 131 & 176 \\
\hline & LS & 74.0 & 118.9 & 166.4 & 55 & 101 & 144 & 91 & 142 & 198 \\
\hline & MReW & 91.0 & 140.0 & 192.6 & 56 & 102 & 143 & 146 & 199 & 275 \\
\hline & $\mathrm{MReO}$ & 64.4 & 95.0 & 129.6 & 48 & 77 & 106 & 112 & 147 & 188 \\
\hline & Random & 92.7 & 141.5 & 193.5 & 60 & 100 & 139 & 160 & 222 & 301 \\
\hline \multirow[t]{7}{*}{ Reman 5} & IABC & 52.3 & 84.5 & 116.3 & 44 & 82 & 119 & 59 & 88 & 116 \\
\hline & MinEnd & 88.1 & 140.6 & 193.6 & 82 & 132 & 184 & 103 & 150 & 206 \\
\hline & GS & 110.6 & 172.4 & 234.8 & 100 & 151 & 205 & 138 & 209 & 273 \\
\hline & LS & 143.5 & 217.5 & 291.4 & 120 & 182 & 242 & 166 & 248 & 334 \\
\hline & MReW & 147.6 & 234.8 & 317.4 & 111 & 173 & 230 & 237 & 324 & 418 \\
\hline & $\mathrm{MReO}$ & 106.2 & 165.2 & 223.9 & 88 & 139 & 194 & 166 & 233 & 314 \\
\hline & Random & 141.5 & 224.8 & 305.3 & 103 & 181 & 250 & 227 & 317 & 416 \\
\hline \multirow[t]{7}{*}{ Reman 6} & IABC & 44.0 & 72.8 & 98.9 & 39 & 71 & 98 & 44 & 75 & 104 \\
\hline & MinEnd & 70.8 & 118.7 & 162.0 & 62 & 100 & 139 & 67 & 134 & 186 \\
\hline & GS & 96.0 & 156.1 & 213.9 & 84 & 133 & 173 & 108 & 178 & 246 \\
\hline & LS & 109.6 & 178.0 & 243.3 & 83 & 154 & 215 & 136 & 214 & 293 \\
\hline & MReW & 142.2 & 223.1 & 302.8 & 94 & 162 & 219 & 219 & 313 & 415 \\
\hline & $\mathrm{MReO}$ & 102.8 & 153.5 & 204.8 & 66 & 114 & 153 & 162 & 210 & 271 \\
\hline & Random & 133.2 & 212.2 & 288.0 & 86 & 162 & 221 & 232 & 314 & 411 \\
\hline \multirow[t]{7}{*}{ Reman 7} & IABC & 61.0 & 107.9 & 153.2 & 63 & 105 & 148 & 60 & 113 & 157 \\
\hline & MinEnd & 96.9 & 167.2 & 233.6 & 94 & 152 & 214 & 100 & 179 & 254 \\
\hline & GS & 132.9 & 228.4 & 315.7 & 112 & 205 & 286 & 153 & 255 & 354 \\
\hline & LS & 149.8 & 265.4 & 368.5 & 136 & 236 & 330 & 169 & 297 & 414 \\
\hline & MReW & 189.8 & 322.5 & 446.9 & 134 & 258 & 366 & 329 & 471 & 631 \\
\hline & $\mathrm{MReO}$ & 159.1 & 248.1 & 336.0 & 100 & 177 & 248 & 231 & 342 & 446 \\
\hline & Random & 200.6 & 331.1 & 453.7 & 139 & 250 & 351 & 351 & 492 & 646 \\
\hline \multirow[t]{7}{*}{ Reman 8} & IABC & $\mathbf{5 7 . 8}$ & 93.5 & 127.0 & 53 & 88 & 122 & 63 & 96 & 133 \\
\hline & MinEnd & 84.9 & 141.1 & 192.8 & 83 & 132 & 172 & 95 & 153 & 206 \\
\hline & GS & 120.2 & 202.2 & 278.0 & 102 & 178 & 251 & 139 & 231 & 317 \\
\hline & LS & 143.5 & 239.1 & 329.8 & 131 & 207 & 282 & 173 & 284 & 390 \\
\hline & MReW & 228.9 & 358.1 & 485.7 & 152 & 274 & 374 & 326 & 443 & 581 \\
\hline & $\mathrm{MReO}$ & 130.2 & 204.9 & 279.3 & 103 & 172 & 231 & 199 & 274 & 367 \\
\hline & Random & 208.9 & 331.9 & 451.7 & 134 & 240 & 330 & 350 & 482 & 643 \\
\hline
\end{tabular}




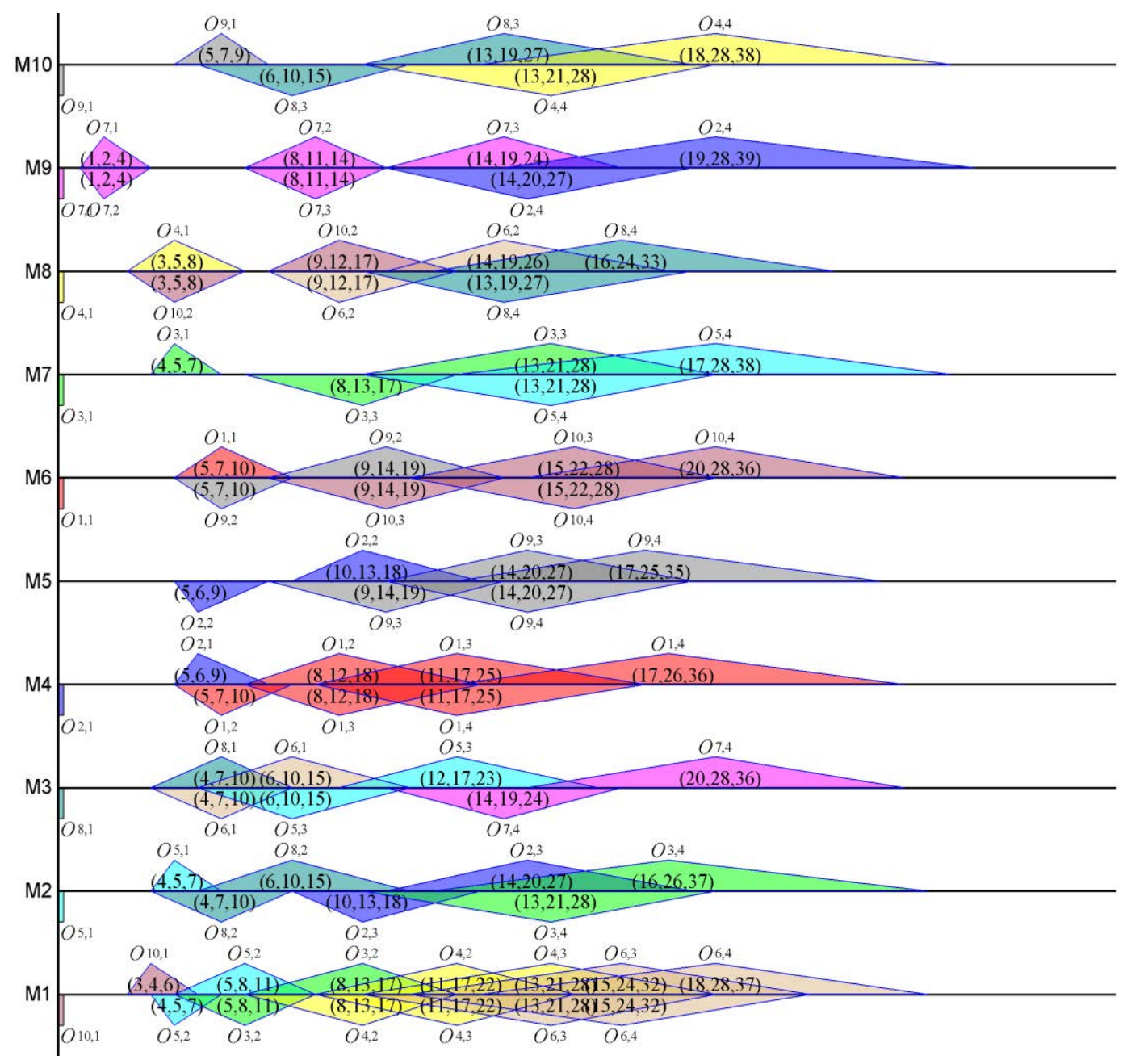

Fig. 6 Maximum fuzzy completion time Gantt chart of case 1 by IABC

Table 7 CPU time and generation of IABC algorithm for eight Reman instances

\begin{tabular}{lrrrr}
\hline Instance & CPU time & Generation & Instance & CPU time \\
\hline Reman 1 & 0.44 & 1000 & Reman 5 & 30.45 \\
Reman 2 & 1.72 & 1000 & Reman 6 & 33.75 \\
Reman 3 & 2.29 & 1000 & Reman7 & 4000 \\
Reman 4 & 3.23 & 1000 & Reman8 & 4000 \\
\hline
\end{tabular}

Notes: $2.40 \mathrm{GHz} \mathrm{CPU}$ 


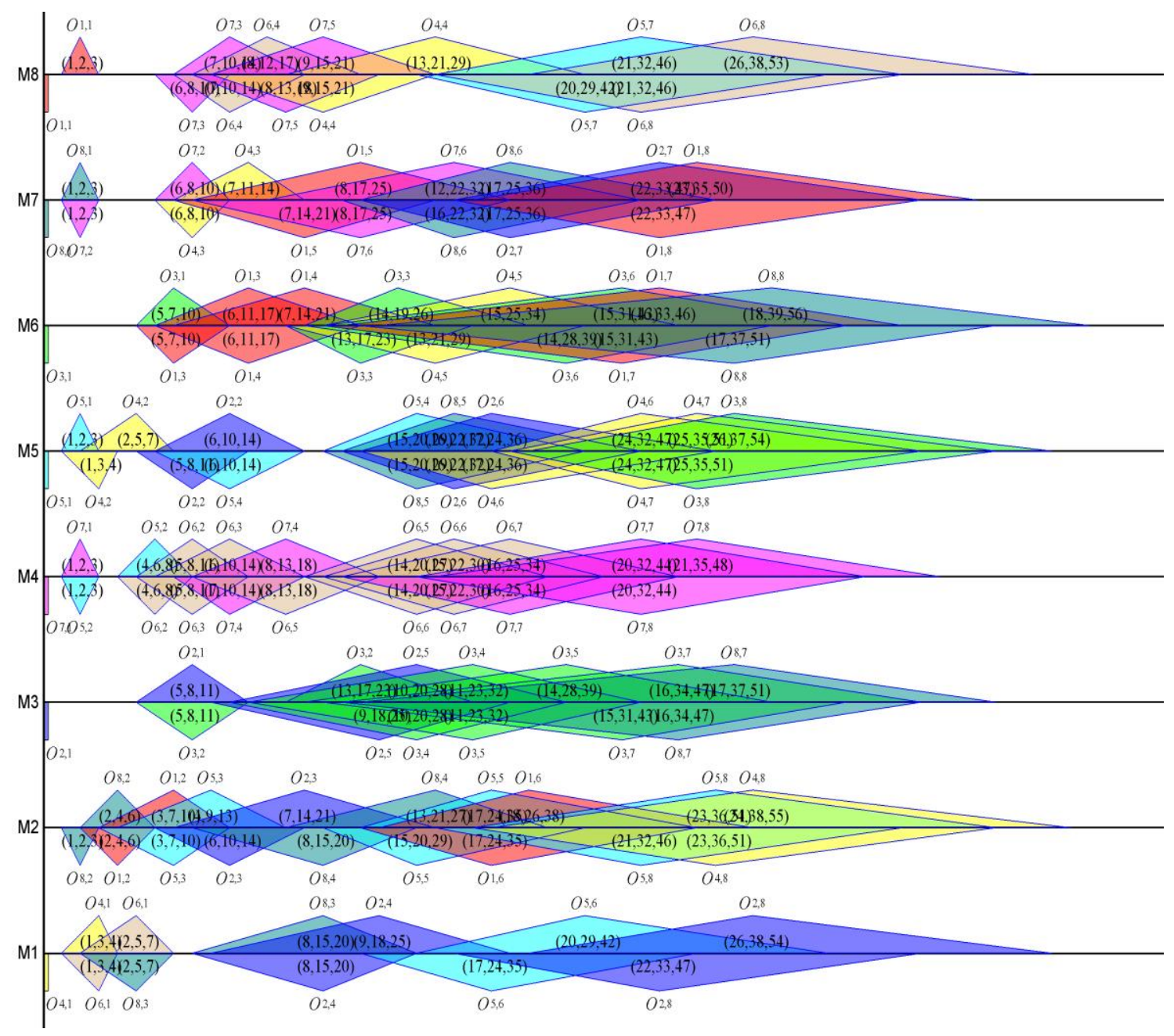

Fig. 7 Maximum fuzzy completion time Gantt chart of Reman 2 by IABC

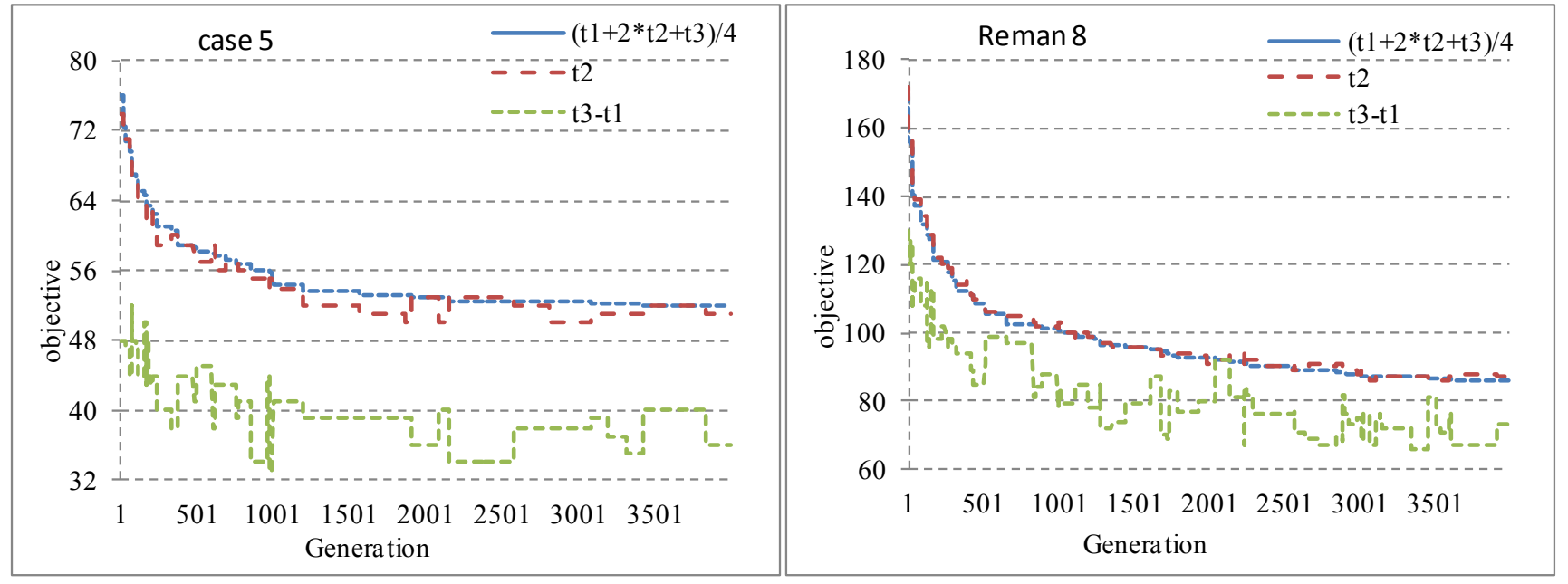

Fig. 8 Maximum fuzzy completion time convergence curves of case 5 and Reman 8 


\subsection{Fuzzy maximum machine workload objective}

For maximum fuzzy machine workload objective, we compared IABC algorithm to six heuristics, namely MinEnd, GS, LS, MReW, MaxReO and random rule. To show IABC algorithm performance, the following formula is employed:

$$
\operatorname{Imp}(i)=\frac{\left(t_{1}^{i}+2 t_{2}^{i}+t_{3}^{i}\right) / 4-\left(t_{1}^{0}+2 t_{2}^{0}+t_{3}^{0}\right) / 4}{\left(t_{1}^{0}+2 t_{2}^{0}+t_{3}^{0}\right) / 4} \times 100 \%
$$

there $t_{1}^{i}, t_{2}^{i}$ and $t_{3}^{i}$ are the results of $i^{\text {th }}$ heuristic represented by TFN; $t_{1}^{0}, t_{2}^{0}$ and $t_{3}^{0}$ are the result of IABC algorithm represented by TFN. $\left(t_{1}^{i}+2 t_{2}^{i}+t_{3}^{i}\right) / 4$ is the first criterion to compare two TFNs. Since the results by IABC algorithm are better than those by the six heuristics, the first criterion is enough to compare them. It is clear that the larger the $\operatorname{Imp}(i)$ is, IABC algorithm is more competitive than $i^{\text {th }}$ heuristic. For five cases inset one, the maximum fuzzy machine workload results of IABC algorithm and $\operatorname{Imp}(i)$ values of six heuristics are shown in Table 8 . It can be seen from Table 8 that the average results by six heuristics are larger than those of IABC by at least $10.6 \%$ for five cases. The best values and worst values by six heuristics are larger than those of IABC by at least $4.6 \%$ and $14 \%$ for five cases, respectively.

For eight instances in set two, the maximum fuzzy machine workload results of IABC and six heuristics are evaluated. The $\operatorname{Imp}(i)$ results of six heuristics to $\mathrm{IABC}$ algorithm are also computed. All the results are shown in Table 9. It can be seen from Table 9 that IABC algorithm can improve the average result, best value and worst value results by six heuristics. For instance Reman 1, IABC find the same result in 30 runs because this instance is a small-scale problem with 5-job, 4-machine and 23-operation. The average results of six heuristics are larger than those obtained by IABC by at least $16.7 \%$ for eight remanufacturing instances. The best values of six heuristics are larger than those obtained by IABC by at least $8.0 \%$. Except for instance Reman 1, the best values by six heuristics are larger than those obtained by IABC by at least $14.4 \%$. The worst values of the six heuristics are larger than those of IABC by at least $20.3 \%$.

To show the maximum machine workload results by IABC clearly, Fig. 9 and Fig. 10 show the best fuzzy Gantt charts of case 1 and instance Reman 2. The maximum fuzzy machine workload of case1 is $(17,25,35)$ in the best solution while the maximum fuzzy machine workload of instance Reman 2 is
$(13,30,41)$. In addition, the CPU time and generation of IABC algorithm are shown in Table 10. For five cases in set one and the previous four instances in set two, the generations are 1000 and the CPU times are less than 3.5 seconds. For the last four instances in set two, the generations are 4000 and the CPU times are $25.23,30.07,66.65$ and 107.97 seconds, respectively. With respect to the scale of problems, the CPU time is very short for all thirteen problems.

To show the convergence of IABC for maximum fuzzy machine workload objective, Fig. 11 presents the curves of three ranking criteria results by IABC for case 5 and Reman 8 . Similar to convergence of maximum fuzzy completion time, the first ranking criterion is non-increasing for two instances. The second and third ranking criteria may increase or decrease while the third ranking criterion has larger fluctuations than the second one. In summary, IABC algorithm has good performance for fuzzy maximum machine workload objective for FJSP with fuzzy processing time.

For fuzzy maximum machine workload objective, this study is the first to consider in FJSP with fuzzy processing time. To solve the five benchmark cases in set one and the eight remanufacturing instances in set two, we first test the results by MinEnd, GS, LS, MReW, MReO and random heuristics. The IABC algorithm is compared the above heuristics by evaluating the percentage improvement. IABC algorithm can improve the results by heuristics for both five benchmark cases and eight remanufacturing instances obviously. The $\mathrm{ABC}$ algorithm has been integrated into remanufacturing scheduling system for more real-life instances.

Hence, IABC algorithm is feasible for fuzzy maximum completion time and fuzzy maximum machine workload objectives. The scheduling solutions by IABC algorithm can match the practical requirement in remanufacturing engineering and can supply high decision support for remanufacturing management.

For the fuzzy maximum machine workload objective, the high quality scheduling solutions by IABC algorithm can balance and control the utilization of all machines effectively. It can effectively avoid machine breakdown due to overload and guarantee remanufacturing smooth progress.

Table 8 Maximum fuzzy machine workload by IABC and improvement to six heuristics for five cases

\begin{tabular}{|c|c|c|c|c|c|c|c|c|c|c|c|c|c|c|c|c|}
\hline \multirow{2}{*}{$\begin{array}{l}\text { Instance } \\
\text { Case1 }\end{array}$} & \multirow{2}{*}{$\begin{array}{l}\text { Algorithm } \\
\text { IABC }\end{array}$} & \multicolumn{3}{|c|}{ Average value } & \multicolumn{2}{|l|}{$\%$} & \multicolumn{3}{|c|}{ Best value } & \multicolumn{2}{|l|}{$\%$} & \multicolumn{3}{|c|}{ Worst value } & \multirow[t]{2}{*}{$\%$} & \\
\hline & & 17.3 & 25.6 & 35.4 & & & 17 & 25 & 35 & & & 19 & 26 & 36 & & \\
\hline & MinEnd & & & & 32.1 & $\uparrow$ & & & & 18.6 & $\uparrow$ & & & & 51.4 & $\uparrow$ \\
\hline & GS & & & & 18.4 & $\uparrow$ & & & & 10.8 & $\uparrow$ & & & & 25.2 & $\uparrow$ \\
\hline & LS & & & & 89.6 & $\uparrow$ & & & & 93.1 & $\uparrow$ & & & & 84.1 & $\uparrow$ \\
\hline & MReW & & & & 152.6 & $\uparrow$ & & & & 71.6 & $\uparrow$ & & & & 240.2 & $\uparrow$ \\
\hline & $\mathrm{MReO}$ & & & & 139.5 & $\uparrow$ & & & & 60.8 & $\uparrow$ & & & & 274.8 & $\uparrow$ \\
\hline & Random & & & & 130.5 & $\uparrow$ & & & & 52.9 & $\uparrow$ & & & & 206.5 & $\uparrow$ \\
\hline Case2 & $\mathrm{IABC}$ & 27.7 & 38.2 & 49.7 & & & 29 & 38 & 46 & & & 28 & 39 & 50 & & \\
\hline & MinEnd & & & & 31.4 & $\uparrow$ & & & & 11.3 & $\uparrow$ & & & & 59.0 & $\uparrow$ \\
\hline
\end{tabular}




\begin{tabular}{|c|c|c|c|c|c|c|c|c|c|c|c|c|c|c|c|c|}
\hline & GS & & & & 16.1 & $\uparrow$ & & & & 4.6 & $\uparrow$ & & & & 23.1 & $\uparrow$ \\
\hline & LS & & & & 95.1 & $\uparrow$ & & & & 98.7 & $\uparrow$ & & & & 92.3 & $\uparrow$ \\
\hline & MReW & & & & 119.4 & $\uparrow$ & & & & 55.0 & $\uparrow$ & & & & 234.0 & $\uparrow$ \\
\hline & $\mathrm{MReO}$ & & & & 147.3 & $\uparrow$ & & & & 54.3 & $\uparrow$ & & & & 278.8 & $\uparrow$ \\
\hline & Random & & & & 131.9 & $\uparrow$ & & & & 58.9 & $\uparrow$ & & & & 230.8 & $\uparrow$ \\
\hline \multirow[t]{7}{*}{ Case3 } & IABC & 27.8 & 39.9 & 52.3 & & & 28 & 38 & 51 & & & 27 & 40 & 57 & & \\
\hline & MinEnd & & & & 28.7 & $\uparrow$ & & & & 7.7 & $\uparrow$ & & & & 46.3 & $\uparrow$ \\
\hline & GS & & & & 13.5 & $\uparrow$ & & & & 12.9 & $\uparrow$ & & & & 20.7 & $\uparrow$ \\
\hline & LS & & & & 76.4 & $\uparrow$ & & & & 81.9 & $\uparrow$ & & & & 72.0 & $\uparrow$ \\
\hline & MReW & & & & 123.0 & $\uparrow$ & & & & 71.0 & $\uparrow$ & & & & 215.2 & $\uparrow$ \\
\hline & $\mathrm{MReO}$ & & & & 137.2 & $\uparrow$ & & & & 49.7 & $\uparrow$ & & & & 222.6 & $\uparrow$ \\
\hline & Random & & & & 117.4 & $\uparrow$ & & & & 60.0 & $\uparrow$ & & & & 201.8 & $\uparrow$ \\
\hline \multirow[t]{7}{*}{ Case 4} & IABC & 19.2 & 29.5 & 42.3 & & & 17 & 29 & 43 & & & 19 & 30 & 44 & & \\
\hline & MinEnd & & & & 34.6 & $\uparrow$ & & & & 18.6 & $\uparrow$ & & & & 52.8 & $\uparrow$ \\
\hline & GS & & & & 17.9 & $\uparrow$ & & & & 13.6 & $\uparrow$ & & & & 26.8 & $\uparrow$ \\
\hline & LS & & & & 32.8 & $\uparrow$ & & & & 35.6 & $\uparrow$ & & & & 30.1 & $\uparrow$ \\
\hline & MReW & & & & 125.5 & $\uparrow$ & & & & 68.6 & $\uparrow$ & & & & 226.0 & $\uparrow$ \\
\hline & $\mathrm{MReO}$ & & & & 120.9 & $\uparrow$ & & & & 45.8 & $\uparrow$ & & & & 225.2 & $\uparrow$ \\
\hline & Random & & & & 103.1 & $\uparrow$ & & & & 48.3 & $\uparrow$ & & & & 173.2 & $\uparrow$ \\
\hline \multirow[t]{7}{*}{ Case 5} & IABC & 35.8 & 53.5 & 74.2 & & & 34 & 51 & 73 & & & 35 & 54 & 79 & & \\
\hline & MinEnd & & & & 21.5 & $\uparrow$ & & & & 15.8 & $\uparrow$ & & & & 32.0 & $\uparrow$ \\
\hline & GS & & & & 10.6 & $\uparrow$ & & & & 11.0 & $\uparrow$ & & & & 14.0 & $\uparrow$ \\
\hline & LS & & & & 44.2 & $\uparrow$ & & & & 49.8 & $\uparrow$ & & & & 41.0 & $\uparrow$ \\
\hline & MReW & & & & 113.8 & $\uparrow$ & & & & 71.8 & $\uparrow$ & & & & 182.0 & $\uparrow$ \\
\hline & $\mathrm{MReO}$ & & & & 111.4 & $\uparrow$ & & & & 65.6 & $\uparrow$ & & & & 159.5 & $\uparrow$ \\
\hline & Random & & & & 120.5 & $\uparrow$ & & & & 64.6 & $\uparrow$ & & & & 267.1 & $\uparrow$ \\
\hline
\end{tabular}

Table 9 Maximum fuzzy machine workload by IABC and six heuristics for eight Reman instances

\begin{tabular}{|c|c|c|c|c|c|c|c|c|c|c|c|c|c|c|c|c|}
\hline \multirow{2}{*}{$\begin{array}{l}\text { Instance } \\
\text { Reman } 1\end{array}$} & \multirow{2}{*}{$\begin{array}{l}\text { Algorithm } \\
\text { IABC }\end{array}$} & \multicolumn{3}{|c|}{ Average value } & \multicolumn{2}{|l|}{$\%$} & \multicolumn{3}{|c|}{ Best value } & \multicolumn{2}{|l|}{$\%$} & \multicolumn{3}{|c|}{ Worst value } & \multicolumn{2}{|l|}{$\%$} \\
\hline & & 13 & 22 & 30 & & & 13 & 22 & 30 & & & 13 & 22 & 30 & & \\
\hline & MinEnd & 19.2 & 29.6 & 39.8 & 35.9 & $\uparrow$ & 13 & 24 & 33 & 8.0 & $\uparrow$ & 29 & 39 & 55 & 86.2 & $\uparrow$ \\
\hline & GS & 16.6 & 27.2 & 36.9 & 24.0 & $\uparrow$ & 13 & 24 & 33 & 8.0 & $\uparrow$ & 20 & 32 & 45 & 48.3 & $\uparrow$ \\
\hline & LS & 15 & 28 & 39 & 26.4 & $\uparrow$ & 15 & 28 & 39 & 26.4 & $\uparrow$ & 15 & 28 & 39 & 26.4 & $\uparrow$ \\
\hline & MReW & 22.6 & 34.9 & 47 & 60.2 & $\uparrow$ & 14 & 24 & 33 & 9.2 & $\uparrow$ & 46 & 64 & 82 & 194.3 & $\uparrow$ \\
\hline & $\mathrm{MReO}$ & 21 & 33.1 & 44.8 & 51.7 & $\uparrow$ & 14 & 24 & 33 & 9.2 & $\uparrow$ & 41 & 55 & 71 & 155.2 & $\uparrow$ \\
\hline & Random & 21.6 & 33.7 & 45.1 & 54.1 & $\uparrow$ & 15 & 26 & 37 & 19.5 & $\uparrow$ & 40 & 55 & 71 & 154.0 & $\uparrow$ \\
\hline \multirow[t]{7}{*}{ Reman 2} & IABC & 16.5 & 29.5 & 41.1 & & & 13 & 30 & 41 & & & 17 & 30 & 42 & & \\
\hline & MinEnd & 27.8 & 44.4 & 60.3 & 51.7 & $\uparrow$ & 23 & 38 & 51 & 31.6 & $\uparrow$ & 38 & 56 & 80 & 93.3 & $\uparrow$ \\
\hline & GS & 23.6 & 37.9 & 52.3 & 30.1 & $\uparrow$ & 20 & 34 & 48 & 19.3 & $\uparrow$ & 31 & 46 & 65 & 58.0 & $\uparrow$ \\
\hline & LS & 31 & 45 & 65 & 59.5 & $\uparrow$ & 31 & 45 & 65 & 63.2 & $\uparrow$ & 31 & 45 & 65 & 56.3 & $\uparrow$ \\
\hline & MReW & 32.1 & 52 & 71.1 & 77.7 & $\uparrow$ & 24 & 39 & 53 & 36.0 & $\uparrow$ & 58 & 86 & 111 & 186.6 & $\uparrow$ \\
\hline & $\mathrm{MReO}$ & 33.6 & 53.5 & 73.8 & 83.9 & $\uparrow$ & 26 & 41 & 54 & 42.1 & $\uparrow$ & 63 & 88 & 120 & 201.7 & $\uparrow$ \\
\hline & Random & 33.5 & 53.2 & 73.2 & 82.8 & $\uparrow$ & 27 & 39 & 55 & 40.4 & $\uparrow$ & 57 & 78 & 109 & 170.6 & $\uparrow$ \\
\hline \multirow[t]{7}{*}{ Reman 3} & IABC & 32.3 & 53.3 & 73.1 & & & 34 & 53 & 71 & & & 36 & 54 & 70 & & \\
\hline & MinEnd & 45.7 & 72.2 & 97 & 35.4 & $\uparrow$ & 41 & 63 & 82 & 18.0 & $\uparrow$ & 53 & 82 & 111 & 53.3 & $\uparrow$ \\
\hline & GS & 42.8 & 67.9 & 91.3 & 27.3 & $\uparrow$ & 37 & 61 & 88 & 17.1 & $\uparrow$ & 50 & 75 & 99 & 39.7 & $\uparrow$ \\
\hline & LS & 51 & 76 & 102 & 43.9 & $\uparrow$ & 51 & 76 & 102 & 44.5 & $\uparrow$ & 51 & 76 & 102 & 42.5 & $\uparrow$ \\
\hline & MReW & 56.4 & 86.6 & 114.8 & 62.5 & $\uparrow$ & 40 & 64 & 85 & 19.9 & $\uparrow$ & 96 & 129 & 167 & 143.5 & $\uparrow$ \\
\hline & $\mathrm{MReO}$ & 58.2 & 90.4 & 121.1 & 69.9 & $\uparrow$ & 33 & 62 & 88 & 16.1 & $\uparrow$ & 93 & 132 & 174 & 148.1 & $\uparrow$ \\
\hline & Random & 56.5 & 87.2 & 116.7 & 64.0 & $\uparrow$ & 43 & 68 & 91 & 28.0 & $\uparrow$ & 91 & 126 & 165 & 137.4 & $\uparrow$ \\
\hline \multirow[t]{7}{*}{ Reman 4} & IABC & 21.4 & 37.5 & 53.1 & & & 28 & 36 & 48 & & & 22 & 37 & 56 & & \\
\hline & MinEnd & 36 & 53.2 & 73.5 & 44.4 & $\uparrow$ & 33 & 46 & 65 & 28.4 & $\uparrow$ & 50 & 67 & 89 & 79.6 & $\uparrow$ \\
\hline & GS & 36.9 & 50.9 & 68.8 & 38.8 & $\uparrow$ & 29 & 45 & 60 & 20.9 & $\uparrow$ & 42 & 60 & 85 & 62.5 & $\uparrow$ \\
\hline & LS & 46 & 72 & 103 & 96.0 & $\uparrow$ & 46 & 72 & 103 & 98.0 & $\uparrow$ & 46 & 72 & 103 & 92.8 & $\uparrow$ \\
\hline & MReW & 49.9 & 73.2 & 99.7 & 98.0 & $\uparrow$ & 39 & 58 & 81 & 59.5 & $\uparrow$ & 89 & 111 & 146 & 200.7 & $\uparrow$ \\
\hline & $\mathrm{MReO}$ & 55.9 & 80.9 & 109.5 & 118.9 & $\uparrow$ & 42 & 59 & 79 & 61.5 & $\uparrow$ & 76 & 108 & 145 & 187.5 & $\uparrow$ \\
\hline & Random & 52.2 & 74.2 & 100.9 & 101.7 & $\uparrow$ & 40 & 56 & 76 & 54.1 & $\uparrow$ & 73 & 103 & 143 & 177.6 & $\uparrow$ \\
\hline
\end{tabular}




\begin{tabular}{|c|c|c|c|c|c|c|c|c|c|c|c|c|c|c|c|c|}
\hline \multirow[t]{7}{*}{ Reman 5} & IABC & 43.5 & 74.4 & 104.9 & & & 36 & 75 & 109 & & & 43 & 74 & 108 & & \\
\hline & MinEnd & 64.7 & 103.7 & 141.5 & 39.2 & $\uparrow$ & 53 & 95 & 128 & 25.8 & $\uparrow$ & 74 & 121 & 165 & 60.9 & $\uparrow$ \\
\hline & GS & 55.6 & 89.5 & 122.5 & 20.2 & $\uparrow$ & 50 & 84 & 120 & 14.6 & $\uparrow$ & 60 & 96 & 130 & 27.8 & $\uparrow$ \\
\hline & LS & 72 & 101 & 137 & 38.3 & $\uparrow$ & 72 & 101 & 137 & 39.3 & $\uparrow$ & 72 & 101 & 137 & 37.5 & $\uparrow$ \\
\hline & MReW & 89.2 & 138 & 186.3 & 85.6 & $\uparrow$ & 67 & 104 & 139 & 40.3 & $\uparrow$ & 128 & 183 & 244 & 146.8 & $\uparrow$ \\
\hline & $\mathrm{MReO}$ & 95 & 146.1 & 196.1 & 96.3 & $\uparrow$ & 67 & 105 & 144 & 42.7 & $\uparrow$ & 149 & 208 & 273 & 180.3 & $\uparrow$ \\
\hline & Random & 83.4 & 134.3 & 182.4 & 79.8 & $\uparrow$ & 61 & 101 & 135 & 34.9 & $\uparrow$ & 132 & 190 & 255 & 156.5 & $\uparrow$ \\
\hline \multirow[t]{7}{*}{ Reman 6} & IABC & 34.5 & 62 & 86.2 & & & 30 & 62 & 87 & & & 38 & 63 & 85 & & \\
\hline & MinEnd & 52.8 & 87.4 & 119 & 41.6 & $\uparrow$ & 45 & 77 & 103 & 25.3 & $\uparrow$ & 63 & 100 & 140 & 61.8 & $\uparrow$ \\
\hline & GS & 45.7 & 76.2 & 104.1 & 23.5 & $\uparrow$ & 41 & 71 & 100 & 17.4 & $\uparrow$ & 54 & 84 & 111 & 33.7 & $\uparrow$ \\
\hline & LS & 56 & 88 & 119 & 43.4 & $\uparrow$ & 56 & 88 & 119 & 45.6 & $\uparrow$ & 56 & 88 & 119 & 41.0 & $\uparrow$ \\
\hline & MReW & 77.4 & 118 & 159.4 & 93.2 & $\uparrow$ & 52 & 84 & 115 & 39.0 & $\uparrow$ & 119 & 173 & 229 & 178.7 & $\uparrow$ \\
\hline & $\mathrm{MReO}$ & 69.1 & 109 & 148.5 & 78.0 & $\uparrow$ & 46 & 79 & 107 & 29.0 & $\uparrow$ & 136 & 186 & 250 & 204.4 & $\uparrow$ \\
\hline & Random & 64.9 & 105.6 & 143.4 & 71.4 & $\uparrow$ & 50 & 85 & 119 & 40.7 & $\uparrow$ & 127 & 178 & 241 & 190.8 & $\uparrow$ \\
\hline \multirow[t]{7}{*}{ Reman 7} & $\mathrm{IABC}$ & 50.5 & 97 & 138.5 & & & 49 & 97 & 137 & & & 50 & 97 & 145 & & \\
\hline & MinEnd & 75.5 & 129.4 & 181.6 & 34.7 & $\uparrow$ & 63 & 116 & 166 & 21.3 & $\uparrow$ & 90 & 144 & 196 & 47.6 & $\uparrow$ \\
\hline & GS & 67.7 & 115.6 & 162.2 & 20.4 & $\uparrow$ & 65 & 111 & 158 & 17.1 & $\uparrow$ & 76 & 122 & 166 & 24.9 & $\uparrow$ \\
\hline & LS & 66 & 122 & 172 & 25.8 & $\uparrow$ & 66 & 122 & 172 & 26.8 & $\uparrow$ & 66 & 122 & 172 & 23.9 & $\uparrow$ \\
\hline & MReW & 115.8 & 188.8 & 259.2 & 96.5 & $\uparrow$ & 79 & 146 & 198 & 49.7 & $\uparrow$ & 179 & 251 & 340 & 162.5 & $\uparrow$ \\
\hline & $\mathrm{MReO}$ & 107.8 & 181.5 & 249.2 & 88.0 & $\uparrow$ & 77 & 137 & 195 & 43.7 & $\uparrow$ & 169 & 263 & 354 & 169.7 & $\uparrow$ \\
\hline & Random & 101.4 & 174.4 & 240.5 & 80.3 & $\uparrow$ & 78 & 139 & 200 & 46.3 & $\uparrow$ & 157 & 233 & 313 & 140.6 & $\uparrow$ \\
\hline \multirow[t]{7}{*}{ Reman8 } & IABC & 40.6 & 75.3 & 106.8 & & & 42 & 74 & 101 & & & 44 & 77 & 107 & & \\
\hline & MinEnd & 59.6 & 100.3 & 138.9 & 33.9 & $\uparrow$ & 52 & 91 & 129 & 24.7 & $\uparrow$ & 71 & 120 & 163 & 55.4 & $\uparrow$ \\
\hline & GS & 50 & 88.1 & 121.5 & 16.7 & $\uparrow$ & 42 & 85 & 121 & 14.4 & $\uparrow$ & 49 & 95 & 128 & 20.3 & $\uparrow$ \\
\hline & LS & 62 & 101 & 139 & 35.2 & $\uparrow$ & 62 & 101 & 139 & 38.5 & $\uparrow$ & 62 & 101 & 139 & 32.1 & $\uparrow$ \\
\hline & MReW & 90.8 & 151.1 & 207.3 & 101.4 & $\uparrow$ & 61 & 110 & 156 & 50.2 & $\uparrow$ & 158 & 215 & 286 & 186.6 & $\uparrow$ \\
\hline & $\mathrm{MReO}$ & 81.4 & 140 & 192.4 & 85.8 & $\uparrow$ & 51 & 110 & 161 & 48.5 & $\uparrow$ & 139 & 200 & 266 & 163.9 & $\uparrow$ \\
\hline & Random & 93.6 & 152.7 & 206.8 & 103.3 & $\uparrow$ & 55 & 108 & 149 & 44.3 & $\uparrow$ & 154 & 227 & 301 & 198.0 & $\uparrow$ \\
\hline
\end{tabular}

Table 10 CPU time and generation of IABC algorithm for all instances

\begin{tabular}{lrrrr}
\hline Instance & CPU time & Generation & Instance & CPU time \\
\hline case 1 & 1.01 & 1000 & Reman 3 & 2.24 \\
case 2 & 1.01 & 1000 & Reman 4 & 3.32 \\
case 3 & 1.37 & 1000 & Reman 5 & 25.23 \\
case 4 & 1.36 & 1000 & Reman 6 & 1000 \\
case 5 & 2.59 & 1000 & Reman7 & 4007 \\
Reman 1 & 0.48 & 1000 & Reman8 & 66.65 \\
Reman 2 & 1.76 & 1000 & & 4007.97 \\
\hline
\end{tabular}

Notes: $2.40 \mathrm{GHz} \mathrm{CPU}$ 


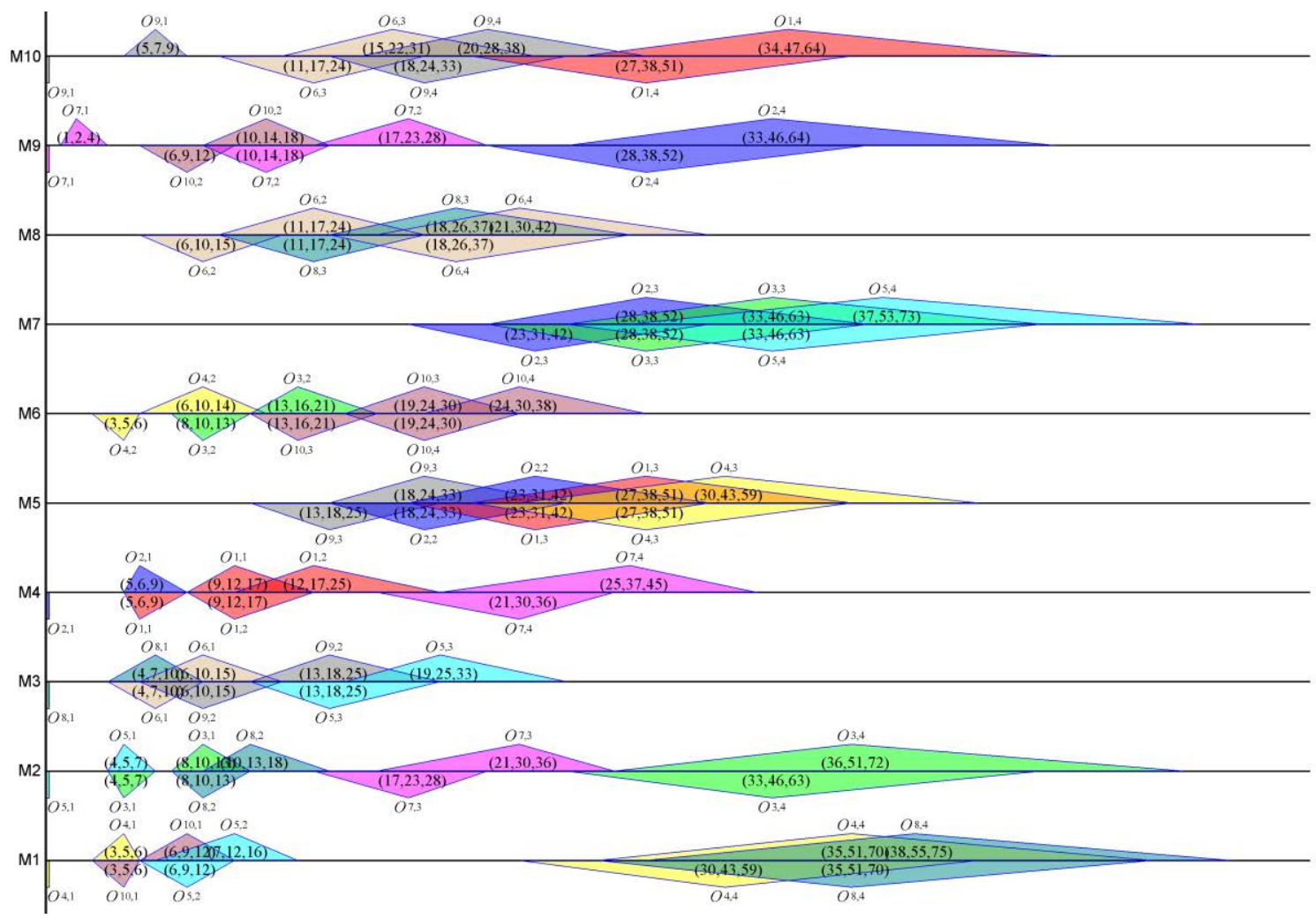

Fig. 9 Maximum fuzzy machine workload Gantt chart of case 1 by IABC

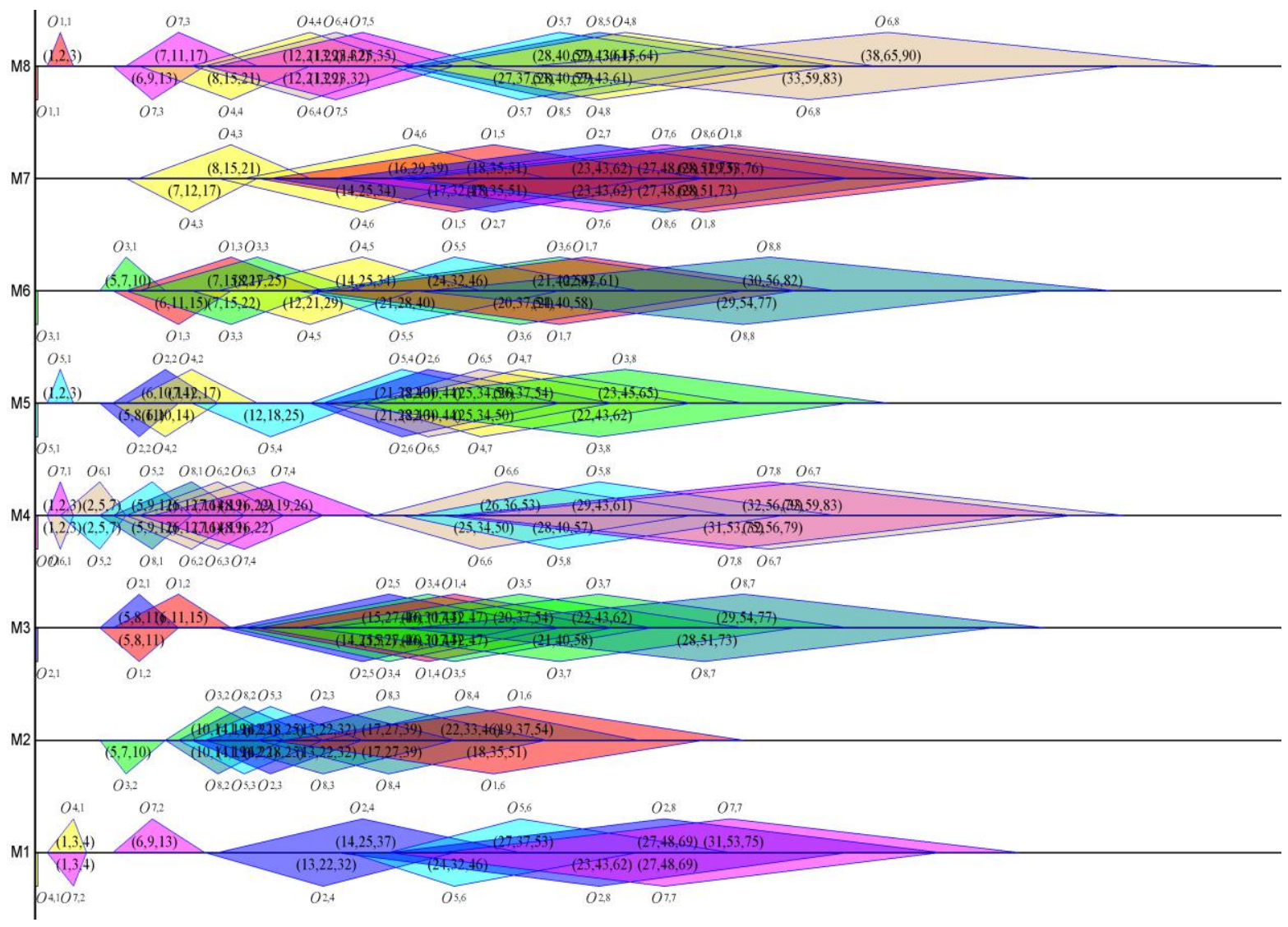

Fig. 10 Maximum fuzzy machine workload Gantt chart of Reman 2 by IABC 


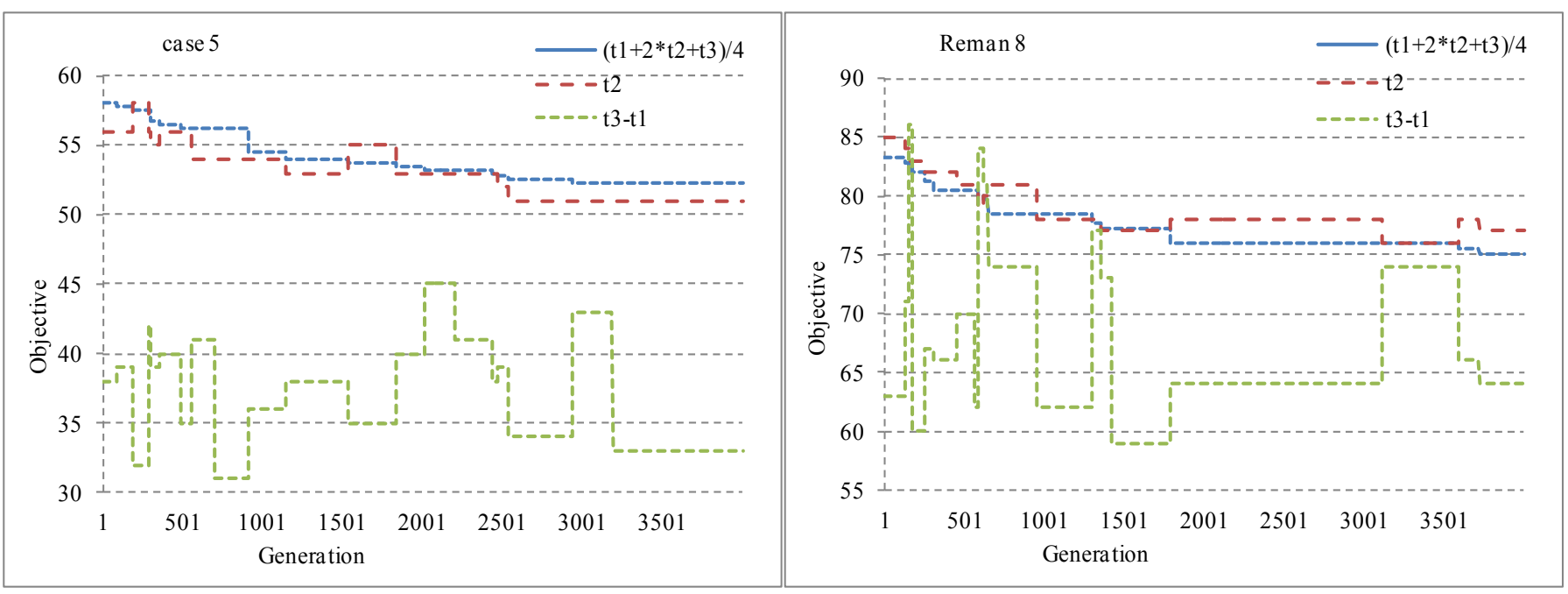

Fig. 11 Maximum fuzzy machine workload convergence curves of case 5 and Reman 8

\section{Conclusions and future works}

In this study, a swarm intelligent algorithm, namely IABC, is proposed to solve FJSP with a practical field, remanufacturing scheduling problem with uncertainty processing time. Fuzzy maximum completion time and fuzzy maximum machine workload are evaluated. The results by IABC algorithm have better competitiveness than the compare algorithms for benchmark cases and real-life instances from remanufacturing. The high quality scheduling solutions and very reasonable computation time make the IABC algorithm satisfying the practical requirements of remanufacturing engineering. The proposed IABC algorithm and the scheduling strategy have been integrated in the manufacturing and remanufacturing planning and scheduling system in SIMTech, Singapore and applied to real-life remanufacturing orders in some remanufacturing companies. These practical applications can verify the feasibility of the schedules by our scheduling strategies and algorithms. The IABC algorithm can be taken as a part of expert and intelligent system for decision support of remanufacturing management.

Even though this study proposed an effective IABC algorithm for remanufacturing scheduling problem. There are some limitations that should be improved in future research work. This study just considered uncertainty processing time constraint in remanufacturing. There are several scheduling related constraints in remanufacturing engineering and management, e.g. new job insertion. This study consider the maximum completion time objective and maximum machine workload objective respectively. In real-life shop floor. Different scheduling objectives should be considered at the same time to satisfy the multiple scheduling requirements.

For the future work, we will deal with the uncertainty of the processing time by using stochastic scheduling strategy. There are also some research topics that can be taken as parts of expert and intelligent systems. 1) Multiple constraints modelling problems for developing expert and intelligent system for remanufacturing management. 2) Solving multi-objective scheduling problems in remanufacturing management. 3) Develop intelligent planning and scheduling algorithms with high performance for remanufacturing engineering decision support. 4) Developing remanufacturing planning and scheduling expert and intelligent system that can satisfy real-life remanufacturing requirements.

\section{Acknowledgements}

This research is partially supported by the National Science Foundation of China under Grant 51575212, 61104179, Program for New Century Excellent Talents in University (Grant No. NCET-13-0106), Science Foundation of Hubei Province in China (Grant No. 2015CFB560), Program of Shandong Province Higher Education Science and Technology under Grant J14LN28, Specialized Research Fund for the Doctoral Program of Higher Education (Grant No. 20130042110035), Key Laboratory Basic Research Foundation of Education Department of Liaoning Province (LZ2014014), and Open Research Fund Program of the State Key Laboratory of Digital Manufacturing Equipment and Technology, Huazhong University of Science and Technology, China.

\section{Reference}

Akay B, Karaboga D. (2012). A modified artificial bee colony algorithm for real-parameter optimization. Information Sciences, 192, 120142.

Banharnsakun A., Sirinaovakul B., and Achalakul T. (2012). Job shop scheduling with the best-so-far ABC. Engineering Application of Artificial Intelligence, 25(3), 583-593.

Brandimarte, P. (1993). Routing and scheduling in a flexible job shop by tabu search. Annual Operations Research, 41(3), 157-183.

Bruker, P., \& Schlie, R. (1990). Job-shop scheduling with multi-purpose machines. Computing, 45(4), 369-375.

Demir Y., İşleyen S. K. (2014). An effective genetic algorithm for 
flexible job shop scheduling with overlapping in operations. International Journal of Production Research, 52(13), 3905-3921.

Ferguson, M. (2009). The value of quality grading in remanufacturing. Production and Operations Management, 18, 300-314.

Gao K.Z., Suganthan P.N., Pan Q.K., Chua T.J., Cai T.X., Chong C.S. (2014a). Discrete harmony search algorithm for flexible job shop scheduling problem with multiple objectives. Journal of Intelligent Manufacturing, Online.

Gao K.Z., Suganthan P.N., Pan Q.K., Chua T.J., Cai T.X., Chong C.S. (2014b). Pareto-based grouping discrete harmony search algorithm for multi-objective flexible job shop scheduling. Information sciences, 289, 76-90.

Gao K.Z., Suganthan P.N., Chua T.J., Cai T.X., Chong C.S., Pan Q.K. (2015). A two-stage artificial bee colony algorithm scheduling flexible job-shop scheduling problem. Expert System with Applications, 42(21), 7652-7663.

Gao, J., Sun, L. Y., \& Gen, M. (2008). A hybrid genetic and variable neighborhood descent algorithm for flexible job shop scheduling problems. Computers Operations Research, 35(9), 2892-2907.

Garey M.R., Johnson D.S., Sethi R. (1976). The complexity of flow shop and job shop scheduling. Mathematics of Operations Research, 1(2), 117-129.

Huang Y.M., Lin J.C. (2011). A new bee colony optimization algorithm with idle-time-based filtering scheme for open shop-scheduling problems. Expert Systems with Applications, 38(5), 5438-5447.

Jiang Z.Q., Zuo L., E M.C. (2014). Study on multi-objective flexible job shop scheduling problem considering energy consumption. Journal of Industrial Engineering and Management, 7(3), 589-604.

Junior, M. L., \& Filho, M. G. (2012). Production planning and control for remanufacturing: Literature review and analysis. Production Planning \& Control: The Management of Operations, 23(6), 419435.

Karaboga, D. (2005). An idea based on honey bee swarm for numerical optimization. Technical Report TR06. Turkey: Computer Engineering Department, Erciyes University.

Karaboga, D., \& Akay, B. (2009). A comparative study of artificial bee colony algorithm. Applied Mathematica and Computation, 24(1), 108-132.

Karthikeyan S., Asokan P., Nickolas S. (2014). A hybrid discrete firefly algorithm for multi-objective flexible job shop scheduling problem with limited resource constraints. International Journal of Advanced Manufacturing Technology, 72(9), 1567-1579.

Krupp, J. A. (1993). Structuring bills of material for automotive remanufacturing. Production and Inventory Management Journal, 34, 46-52.

Lei D.M. (2010). Fuzzy job shop scheduling problem with availability constraints. Computers \& Industrial Engineering, 58(4), 610-617.

Lei D.M. (2010). A genetic algorithm for flexible job shop scheduling with fuzzy processing time. International Journal of Production Research, 48(10), 2995-3013.

Lei D.M. (2012). Co-evolutionary genetic algorithm for fuzzy flexible job shop scheduling. Applied soft computing, 12(8), 2237-2245.

Li, J. Q., Pan, Q. K., \& Gao, K. Z. (2011). Pareto-based discrete artificial bee colony algorithm for multi-objective flexible job shop scheduling problems. Internal Journal of Advanced Manufacturing Technology, 55(9-12), 1159-1169.

Lund, R. I. (1984). Remanufacturing. Technology Review, 87, 18-23.

Pan Q.K., Tasgetirern M.F., Suganthan P.N., Chua T.J. (2011). A discrete artificial bee colony algorithm for the lot-streaming flow shop scheduling problem. Information Sciences, 181(12), 24552468.

Pezzella F., Morganti G., Ciaschetti G. (2008). A genetic algorithm for the flexible job-shop scheduling problem. Computers \& Operations Research, 35(10), 3202-3212.

Rossi A. (2014). Flexible job shop scheduling with sequence-dependent setup and transportation times by ant colony with reinforced pheromone relationships. International Journal of Production Economics, 153, 253-267.

Thammano A., Ajchara P.A. (2013). A hybrid artificial bee colony algorithm with local search for flexible job shop scheduling problem. Procedia Computer Science, 20, 96-101.

Wang, S. Y., Wang, L., Xu, Y., \& Liu, M. (2013). An effective estimation of distribution algorithm for the flexible job shop scheduling problem with fuzzy processing time. International Journal of Production Research, 51(12), 3778-3793.

Wang, L., Zhou, G., Xu, Y., \& Liu, M. (2012). An enhanced Paretobased artificial bee colony algorithm for the multi-objective flexible job-shop scheduling. International Journal of Advanced Manufacturing Technology, 60(9-12), 1111-1123.

Wang, L., Zhou, G., Xu, Y., \& Liu, M. (2013). A hybrid artificial bee colony algorithm for the fuzzy flexible job-shop scheduling problem. International Journal of Production Research, 51(12), 3593-3608.

Wang, L., Zhou, G., Xu, Y., \& Wang, S. (2012). An effective artificial bee colony algorithm for the flexible job shop scheduling problem. Internal Journal Advanced Manufacturing Technology, 60(1-4), 303-315.

Wang S.J., Yu J.B. (2010). An effective heuristic for flexible job shop scheduling problem with maintenance activities. Computers \& Industrial Engineering, 59(3), 436-447.

Xia W. J., Wu Z. M. (2005). An effective hybrid optimization approach for multi-objective flexible job-shop scheduling problems. Computers \& Industrial Engineering, 48(2), 409-425.

Yazdani, M., Amiri, M., \& Zandieh, M. (2010). Flexible job-shop scheduling with parallel variable neighborhood search algorithm. Expert System with Applications, 37(1), 678-687.

Zhang, G. H., Shao, X. Y., Li, P. G., \& Gao, L. (2009). An effective hybrid particle swarm optimization algorithm for multi-objective flexible job-shop scheduling problem. Computers \& Industrial Engineering, 56(4), 1309-1318.

Zhang R., Wu C. (2011). An artificial bee colony algorithm for the job shop scheduling problem with random processing times. Entropy, 13(9), 1708-1729. 